\title{
Amino modified metal-organic frameworks as pH-responsive nano- platforms for safe delivery of camptothecin
}

\author{
Alejandro Cabrera-García ${ }^{\mathrm{a}}$, Elisa Checa-Chavarria ${ }^{\mathrm{b}}$, Eva Rivero-Buceta ${ }^{\mathrm{a}}$, Victoria Mo- \\ reno $^{\mathrm{c}}$, Eduardo Fernández ${ }^{\mathrm{b}}$, Pablo Botella ${ }^{\mathrm{a}, *}$ \\ ${ }^{a}$ Instituto de Tecnología Química, Universitat Politècnica de València-Consejo Superior de In- \\ vestigaciones Cientificas, Avenida de los Naranjos s/n, 46022 Valencia, Spain \\ ${ }^{b}$ Institute of Bioengineering, Universidad Miguel Hernández, Elche, Spain and Centre for Net- \\ work Biomedical Research (CIBER-BBN), Spain \\ ${ }^{c}$ Neuronal and Tissue Regeneration Lab, Research Centre "Principe Felipe", Valencia, Spain. \\ * To whom correspondence should be addressed.E-mail: pbotella@itq.upv.es. Fax: +34 963879444.
}

\begin{abstract}
MIL-100(Fe) and MIL-101(Fe) metal-organic frameworks (MOFs) are excellent vehicles for drug delivery systems (DDSs) due to their high biocompatibility and stability in physiological fluids, as well as their pore diameter in the mesoporous range. Although they are appropriate for the internal diffusion of 20-(S)-camptothecin (CPT), a strongly cytotoxic molecule with excellent antitumor activity, no stable delivery system has been proposed so far for this drug based in MOFs. We here present novel DDSs based in amine functionalized MIL-100(Fe) and MIL-101(Fe) nanoMOFs with covalently bonded CPT. These CPT nanoplatforms are able to incorporate almost $20 \%$ of this molecule and show high stability at physiological $\mathrm{pH}$, with no non-specific release. Based on their surface charge, some of these CPT loaded nanoMOFs present improved cell internalization in in vitro experiments. Moreover, a strong response to acid $\mathrm{pH}$ is observed, with up to four fold drug discharge at $\mathrm{pH}$ 5, which boost intracellular release by endosomolytic activity. These novel DDSs will help to achieve safe delivery of the
\end{abstract}


very cytotoxic CPT, allowing to reduce the therapeutic dose and minimizing drug secondary effects.

Keywords: metal-organic frameworks, drug delivery, pH-responsive, biodegradability, camptothecin

\section{Introduction}

Current biomedical research focused on the fight against cancer seeks to design new selective treatments, which efficiently kill tumor cells avoiding the undesirable side effects produced by chemotherapy [1]. In this field of application, metal-organic frameworks (MOFs) have been studied as efficient pharmacological vehicles since 2006 [24]. MOFs offer very attractive properties, such as high porosity, structural and compositional tunability and easy surface functionalization making these materials suitable for many different applications [5], such as gas adsorption [6], catalysis [7], non-linear optics [8], or sensors [9]. They take advantage of their lack of toxicity, easy size-reduction to the nanoscale and the intrinsic relative lability of metal ligand bonds, which favors their biodegradability [10]. Moreover, they have been shown to be very efficient as contrast agents in magnetic resonance imaging, computed tomography and optical imaging $[11,12]$, as sensitizing agents in photothermal [13] and photodynamic therapy [14], and as drug delivery systems (DDSs) [11,15-17]. In this context, MOFs belonging to the family of MILs (Materials of Institute Lavoisier), which are formed by carboxylate ligands and iron (III) as a non-toxic cation, have shown enormous potential in the loading and safe release of large drug quantities [18-20].

Besides, 20-(S)-camptothecin (CPT) is a natural alkaloid with strong antitumor activity against a broad spectrum of cancers [21,22]. Since its discovery by Wall et al. in 1966, 
efforts have been done in the implementation of this drug to the current treatments against cancer [23]. However, this molecule has found no clinical application, due to its extremely poor solubility in water and most organic solvents, its low stability at physiological $\mathrm{pH}$, which cleavages its lactone ring to give the little active carboxylate derivative, and its strong toxicity, producing hemorrhagic cystitis and myotoxicity [24,25]. At this point, drug incorporation to stable and biocompatible nanoparticles can minimize these limitations to CPT systemic delivery. In this sense, there are very few works in which CPT molecule has been loaded on the structure of a MOF, always through in situ trapping or via post-synthetic adsorption [26-28], giving very unstable DDSs which suffer of significant non-specific release during transport.

In order to achieve efficient delivery and intracellular CPT discharge, in this work we present novel DDSs based in nanoMOFs structures MIL-100(Fe) and MIL-101(Fe) modified with amino groups. We selected these materials due to their large pore dimensions, in the mesoporous range, making feasible CPT molecule accommodation inside the inner cavities, and we have covalently bonded the drug through specific linkers over the amino groups. The resulting conjugates incorporated to the best of our knowledge the highest CPT quantity reported in a DDS (almost $20 \%$ ) and showed high stability in physiological pH. Moreover, due to their positive charge, CPT containing MIL-101(Fe) derivatives presented promoted cell internalization in in vitro testing, and also deployed a noticeable acid $\mathrm{pH}$-responsive behavior, which can boost drug release after cell uptake at the lysosomal stage, improving the safe delivery and controlled release of the antitumor moiety.

\section{Materials and methods}

All reagents used in this work were of ACS purity or higher, and were obtained from different commercial suppliers. 1,3,5-tribromobenzene (99\%), bis(pinacolato)diboron 
(99\%), potassium acetate (99\%), 1,1'-Bis(diphenylphosphi-no)ferrocenepalladium(II) dichloride $\left(\mathrm{Pd}(\mathrm{dppf}) \mathrm{Cl}_{2}, 98 \%\right)$, methyl 4-bromo-2-aminobenzoate $(98 \%)$, cesium fluoride (99\%), 4-(tert-butoxy)-4-oxobutanoic acid (95\%) and 5-hexynoic acid (95\%) were purchased from Fluorochem. 2-Aminoterephtalic acid (99\%), iron (III) chloride hexahydrate $\left(\mathrm{FeCl}_{3} \cdot 6 \mathrm{H}_{2} \mathrm{O}, 98 \%\right)$, , 4 -dioxane $(99.8 \%)$, sodium sulphate $(99 \%), 1 \mathrm{~N}$ sodium hydroxide aqueous solution $(\mathrm{NaOH})$, hydrochloric acid solution $(\mathrm{HCl}, 37 \%)$, acetic acid $(\mathrm{AcOH}$, 99\%), 4-(dimethylamino)pyridine (DMAP, 99\%), N,N-diisopropylcarbodiimide (DIC, 99\%), trifluoroacetic acid (TFA, 99\%), N-(3-dimethylaminopropyl)N'-ethylcarbodiimide hydrochloride (EDC, 99\%), 1-hydroxybenzotriazole hydrate (HOBT, 97\%), N,N-diisopropylethylamine (DIPEA, 99\%), tert-butyl nitrite (t-BuONO, 96\%), azidotrimethylsilane ( $\mathrm{TMSN}_{3}, 95 \%$ ), tetrakis(acetonitrile)copper(I) hexafluorophosphate $\left(\mathrm{Cu}\left(\mathrm{CH}_{3} \mathrm{CN}\right)_{4} \mathrm{PF}_{6}, 97 \%\right)$, trichloroacetic acid (TCA, 99\%), hydrofluoric acid solution (HF, 40\%), terephthalic acid (98\%) and rhodamine B (RhB, 97\%) were provided by Sigma-Aldrich. Moreover, dimethylformamide (DMF, extra pure) and ammonium chloride (99\%) were acquired from Acros Organics, 1,3,5-tri(4-carboxyphenyl)benzene (BTB, 97\%) from ABCR, camptothecin (CPT, 95\%) from Carbosynth, and HPLC grade solvents from Scharlab. Water was deionized to $18.2 \mathrm{~m} \Omega \cdot \mathrm{cm}^{-1}$ by using a miliQ pack system.

Human cell lines HeLa cervical adenocarcinoma, bone marrow SH-SY5Y neuroblastoma and fibroblast 3T3 were originally obtained from the American Type Culture Collection (Rockville, MD), maintained in MEM (Earle's), DMEM (Dulbecco's Modified Eagle's Medium) and DMEM + F12 respectively, supplemented with $10 \%$ fetal bovine serum (FBS, from Lonza, Verviers, Belgium) and Penicillin/streptomycin $1 \%$ at $37{ }^{\circ} \mathrm{C}$ under a humidified atmosphere of $95 \%$ air and $5-10 \% \mathrm{CO}_{2}$. Various cell imaging reagents were used, Lysotracker Green ${ }^{\circledR}$ (Invitrogen), DRAQ5 ${ }^{\mathrm{TM}}$ (Biostatus) and DAPI (Roche). 


\subsection{Synthesis of amine functionalized Iron (III) MOFs}

Amine MIL-101(Fe) $\left(\mathrm{M} 1-\mathrm{NH}_{2}\right)$ was prepared following a previously reported solvothermal procedure [29]. Briefly, a solution of $0.181 \mathrm{~g}$ of 2 -aminoterephthalic acid ( $1 \mathrm{mmol})$ and $0.541 \mathrm{~g}$ of $\mathrm{FeCl}_{3} \cdot 6 \mathrm{H}_{2} \mathrm{O}(2 \mathrm{mmol})$ in $12.14 \mathrm{~mL}$ of DMF was heated to $110^{\circ} \mathrm{C}$ for 24 h. After cooling down to room temperature, the resulting suspension was filtered off and washed three times with DMF (15 mL each) and another three times with EtOH (15 mL each). Finally, the material was redispersed in $35 \mathrm{~mL}$ of absolute ethanol and centrifuged washing three times at $13336 \mathrm{G}$ for 20 minutes each wash, was dried under vacuum, yielding $0.242 \mathrm{~g}$ of $\mathrm{M} 1-\mathrm{NH}_{2}$.

Amine MIL-100(Fe) (M2-NH2) was prepared in two steps. Firstly, we synthesized the ligand 1,3,5-tris(2-amino-4-carboxyphenyl)benzene $\left(\mathrm{BTB}-\mathrm{NH}_{2}\right)$ as described elsewhere (Supporting Information) [30]. Then, we used this ligand for $\mathrm{M} 2-\mathrm{NH}_{2}$ synthesis through an aging approach of $\mathrm{Fe}^{3+}$ with water and acetic acid $[31,32]$ to give small crystals with a large number of amine groups. $0.161 \mathrm{~g}$ of $\mathrm{FeCl}_{3} \cdot 6 \mathrm{H}_{2} \mathrm{O}(0.60 \mathrm{mmol})$ was dissolved in 15.2 $\mathrm{mL}$ of DMF and then $122 \mu \mathrm{L}$ of mQ water and $498 \mu \mathrm{L}$ of AcOEt were added. The solution was allowed to age for two days at room temperature prior to the addition of $0.191 \mathrm{~g}$ of the BTB-NH 2 ligand $(0.40 \mathrm{mmol})$ were dissolved in $5 \mathrm{~mL}$ of DMF. The resulting mixture was placed in an autoclave and heated at $120^{\circ} \mathrm{C}$ for 24 hours. The solid obtained was collected by filtration and washed three times with DMF, three times with absolute ethanol, redispersed in ethanol and washed by centrifugation 3 times at 27216 $\mathrm{G}$ for 10 minutes. Finally, the solid was dried under vacuum, yielding $0.184 \mathrm{~g}$. 


\subsection{Incorporation of camptothecin to amine functionalized nanoMOFs}

\subsubsection{Synthesis of CPT prodrugs}

For the CPT incorporation over amine functionalized nanoMOFs, CPT was previously linked with a lateral chain by ester bond. We here have prepared two CPT prodrugs with variable covalent bond, 20-OH-hemissucinate camptothecin (CPT-Suc) [33], and camptothecin-5-hexinoate (CPT-HA) [34]. Details on the synthesis and chemical ch

\subsubsection{Covalent linking of 20-OH-hemissucinate camptothecin}

$\mathrm{M} 1-\mathrm{NH}_{2}: 0.242 \mathrm{~g}$ of $\mathrm{M} 1-\mathrm{NH}_{2}$ were dried at $100{ }^{\circ} \mathrm{C}$ under vacuum ( 8 torr) for $24 \mathrm{~h}$ in a $50 \mathrm{~mL}$ 2-neck round bottom flask. $0.042 \mathrm{~g}$ of CPT-Suc $(0.094 \mathrm{mmol}), 0.023 \mathrm{~g}$ of EDC $(0.12 \mathrm{mmol}), 0.025 \mathrm{~g}$ of HOBT $(0.18 \mathrm{mmol})$ and $10 \mathrm{~mL}$ of dry DCM were added to another $50 \mathrm{~mL}$ 2-necked round bottom flask and the mixture was maintained under constant stirring under a $\mathrm{N}_{2}$ atmosphere and at $0{ }^{\circ} \mathrm{C}$ for 30 minutes. After this time, the mixture was added over the dry $\mathrm{M} 1-\mathrm{NH}_{2}$ and then $16.52 \mu \mathrm{L}$ of DIPEA $(0.095 \mathrm{mmol})$ was added, the mixture was stirred for $16 \mathrm{~h}$ at room temperature under $\mathrm{N}_{2}$ atmosphere. The obtained solid was collected by filtration, washed with DCM 3 times and MeOH 3 times and, subsequently, redispersed in $\mathrm{MeOH}$ and washed 5 times. Finally, the sample was dried under vacuum overnight, obtaining $0.249 \mathrm{~g}$ of M1-S-CPT sample.

$\mathrm{M} 2-\mathrm{NH}_{2}$ : The same procedure was followed as for the functionalization of $\mathrm{M} 1-\mathrm{NH}_{2}$, but in this case, reagent quantities were: $0.050 \mathrm{~g} \mathrm{M} 2-\mathrm{NH}_{2}, 0.012 \mathrm{~g} \mathrm{CPT}-\mathrm{Suc}(0.027 \mathrm{mmol})$, $0.005 \mathrm{~g}$ EDC (0.026 mmol), $0.005 \mathrm{~g}$ HOBT $(0.037 \mathrm{mmol})$ and $3.16 \mu \mathrm{L}$ DIPEA (0.018 mmol). This gave $0.044 \mathrm{~g}$ of M2-S-CPT sample.

\subsubsection{Covalent linking of camptothecin-5-hexinoate}

$\mathrm{M} 1-\mathrm{NH}_{2}: 0.050 \mathrm{~g}$ of dry $\left(\mathrm{M} 1-\mathrm{NH}_{2}\right)$ were placed into a $50 \mathrm{~mL}$ 2-neck round bottom flask, $3.0 \mathrm{~mL}$ of anhydrous THF, $0.187 \mathrm{~mL}$ of $\mathrm{t}-\mathrm{BuONO}(1.309 \mathrm{mmol})$ and $0.168 \mathrm{~mL}$ of 
$\mathrm{TMSN}_{3}(1.122 \mathrm{mmol})$ were added following this order. This mixture was allowed to react overnight at room temperature under Ar atmosphere to produce the azide intermediate derivative $\mathrm{M} 1-\mathrm{N}_{3}$. The compound was separated by filtration and washed 3 times with $8 \mathrm{~mL}$ of THF, 3 times with $8 \mathrm{~mL}$ of DCM and another 3 times with $8 \mathrm{~mL}$ of toluene $[35,36]$.

The still wet solid was transferred to a $50 \mathrm{~mL}$ 2-necked round bottom flask under $\mathrm{Ar}$ atmosphere and suspended in $1 \mathrm{~mL}$ of dry and degassed DMF. The suspension was then treated with $0.5 \mathrm{~mL}$ of a solution $0.099 \mathrm{~g}$ of CPT-HA $(0.2244 \mathrm{mmol})$ and was kept stirring at room temperature for $5 \mathrm{~h}$. Subsequently, $0.041 \mathrm{~g}$ of $\mathrm{Cu}^{\mathrm{I}}\left(\mathrm{CH}_{3} \mathrm{CN}\right)_{4} \mathrm{PF}_{6}(0.224$ mmol) dissolved in $0.3 \mathrm{~mL}$ of dry and degassed DMF was added to the mixture. Finally, the reaction mixture was heated at $85^{\circ} \mathrm{C}$ for $14 \mathrm{~h}$ with constant magnetic stirring. Once cooled, the solid was recovered by filtration and washed 3 times with DMF, 3 times with DCM and finally 3 times with $\mathrm{MeOH}$. Then, the solid was redispersed in $\mathrm{MeOH}$ and washed 5 times at $13336 \mathrm{G}$ for 20 minutes each wash, and finally it was dried under vacuum overnight, giving $0.088 \mathrm{~g}$ of M1-C-CPT.

$\mathrm{M} 2-\mathrm{NH}_{2}$ : The same procedure was followed as for the functionalization of $\mathrm{M} 1-\mathrm{NH}_{2}$, but in this case, reagent quantities were: $0.085 \mathrm{~g} \mathrm{M} 2-\mathrm{NH}_{2}, 5.4 \mathrm{~mL}$ THF, $0.457 \mathrm{~mL}$ t-BuONO (3.20 mmol), $0.335 \mathrm{~mL} \mathrm{TMSN}_{3}(2.24 \mathrm{mmol}), 0.231 \mathrm{~g} \mathrm{CPT-HA}(0.52 \mathrm{mmol}), 2.6 \mathrm{~mL}$ DMF, $0.098 \mathrm{~g} \mathrm{Cu}^{\mathrm{I}}\left(\mathrm{CH}_{3} \mathrm{CN}\right)_{4} \mathrm{PF}_{6}(0.53 \mathrm{mmol})$ dissolved in $0.51 \mathrm{~mL}$ of dry and degassed DMF. Gave $0.086 \mathrm{~g}$ of M2-C-CPT.

\subsubsection{Incorporation of camptothecin by adsorption}

For the purpose of comparison with novel DDSs based in MIL nanoMOFs containing covalently bonded CPT we also prepared classical DDSs obtained by single adsorption of the drug over amine functionalized MIL-100(Fe) and MIL-101 (Fe) structures. 
M1-NH2: In order to achieve an efficient adsorption of CPT by the material, $0.100 \mathrm{~g}$ of $\mathrm{M} 1-\mathrm{NH}_{2}$ and $0.201 \mathrm{~g}$ of CPT $(0.58 \mathrm{mmol})$ were mixed in a $50 \mathrm{~mL}$ 2-necked round bottom flask. $3 \mathrm{~mL}$ of dry and degassed DMF were added and the mixture was stirred at 85 ${ }^{\circ} \mathrm{C}$ under an Ar atmosphere overnight. Once cooled, the solid was recovered by filtration and washed 3 times with DMF, 3 times with DCM and finally 3 times with $\mathrm{MeOH}$. Then, the solid was redispersed in $\mathrm{MeOH}$ and washed 5 times at $13336 \mathrm{G}$ for 20 minutes each wash, and finally it was dried under vacuum overnight, yielding $0.099 \mathrm{~g}$ of M1-ACPT.

M2-NH2: The same procedure was followed as for the CPT adsorption inside of M1$\mathrm{NH}_{2}$, but in this case, the amounts used were $0.079 \mathrm{~g} \mathrm{M} 2-\mathrm{NH}_{2}, 0.217 \mathrm{~g} \mathrm{CPT}(0.62 \mathrm{mmol})$ and $3 \mathrm{~mL}$ of dry and degassed DMF. This gave $0.077 \mathrm{~g}$ of M2-A-CPT.

\subsection{Incorporation of rhodamine $B$ to amine functionalized nanoMOFs}

In order to monitor cell internalization and cell tracking processes of MOF nanoparticles, a fluorochrome (Rhodamine $\mathrm{B}, \mathrm{RhB}$ ) was incorporated to $\mathrm{M} 1-\mathrm{NH}_{2}$ and $\mathrm{M} 2-\mathrm{NH}_{2}$ surface by amide bond, obtaining, respectively, $\mathrm{M} 1-\mathrm{RhB}$ and $\mathrm{M} 2-\mathrm{RhB}$ materials.

M1-RhB: $0.155 \mathrm{~g}$ of $\mathrm{M} 1-\mathrm{NH}_{2}$ were dried at $100{ }^{\circ} \mathrm{C}$ under vacuum ( 8 torr) for $24 \mathrm{~h}$ in a $50 \mathrm{~mL}$ 2-neck round bottom flask. $0.0024 \mathrm{~g}$ of $\mathrm{RhB}(0.005 \mathrm{mmol}), 0.0012 \mathrm{~g}$ of EDC $(0.006 \mathrm{mmol}), 0.0013 \mathrm{~g}$ of HOBT $(0.009 \mathrm{mmol})$ and $10 \mathrm{~mL}$ of dry DCM were added to another $50 \mathrm{~mL}$ 2-necked round bottom flask and the mixture was maintained under constant stirring under a $\mathrm{N}_{2}$ atmosphere and at $0{ }^{\circ} \mathrm{C}$ for 30 minutes. After this time, the mixture was added over the dry $\mathrm{M} 1-\mathrm{NH}_{2}$ and then $0.8 \mu \mathrm{L}$ of DIPEA $(0.005 \mathrm{mmol})$ was added, the mixture was stirred for $16 \mathrm{~h}$ at room temperature under $\mathrm{N}_{2}$ atmosphere. Finally, the solid was collected by filtration, washed with DCM 3 times and $\mathrm{MeOH} 3$ times, then, the solid was redispersed in $\mathrm{MeOH}$ and washed 5 times at $13336 \mathrm{G}$ for 20 
minutes each wash, and finally it was dried under vacuum overnight, obtaining $0.147 \mathrm{~g}$ of M1-RhB.

MIL-100(Fe)-RhB: The same procedure was followed as for the functionalization of $\mathrm{M} 1-\mathrm{NH}_{2}$, but in this case, the amounts used were $0.058 \mathrm{~g} \mathrm{M} 2-\mathrm{NH}_{2}, 0.0009 \mathrm{~g} \mathrm{RhB}(0.002$ mmol), $0.0005 \mathrm{~g}$ EDC (0.001 mmol), $0.0006 \mathrm{~g} \mathrm{HOBT}(0.004 \mathrm{mmol})$ and $0.3 \mu \mathrm{L}$ DIPEA (0.005 mmol), giving $0.039 \mathrm{~g}$ of M2-RhB.

\subsection{Materials Characterization}

Liquid ${ }^{1} \mathrm{H}$ NMR spectra were recorded in DMSO- $d_{6}$ at $300 \mathrm{MHz}$, using a Bruker AMX300 instruments. For ${ }^{1} \mathrm{H}$ spectra, chemical shifts are given in parts per million (ppm) and are referenced to the residual solvent peak. Coupling constants $(J)$ are given in Hertz $(\mathrm{Hz}) .{ }^{13} \mathrm{C}$ NMR spectra were recorded at $75 \mathrm{MHz}$ using a Bruker AMX300 instrument. Quadrupole time-of-flight mass spectra (Q-TOF) were recorded on an Aquity UPLC Waters coupled with Xevo Qtof MS with an Aquity UPLC BEH C18 $(1.7 \mu \mathrm{m}, 50$ $\mathrm{x} 21 \mathrm{~mm}$ ) column and using positive electrospray ionization. The products were eluted utilizing a constant solvent mixture $50: 50 \mathrm{v} / \mathrm{v}$ (solvent $\mathrm{A}=0.1 \% \mathrm{CH}_{3} \mathrm{COOH} / \mathrm{CH}_{3} \mathrm{CN}$;

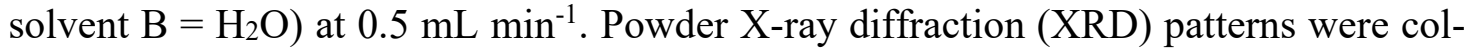
lected on a Philips X'Pert diffractometer equipped with a graphite monochromator, operating at $40 \mathrm{kV}$ and $45 \mathrm{~mA}$ using nickel-filtered $\mathrm{Cu} \mathrm{K} \alpha$ radiation $(\lambda=0.1542 \mathrm{~nm})$. Liquid nitrogen adsorption-desorption isotherms were measured in a Micromeritics Flowsorb apparatus. The surface area and pore diameter calculations were done by the BET-BJH method. Samples for transmission electron microscopy (TEM) were ground finely and directly transferred to carbon coated copper grids. TEM micrographs were collected using a JEOL JEM 2100F microscope operating at $200 \mathrm{kV}$. Infrared spectra were recorded at room temperature in the $400-3900 \mathrm{~cm}^{-1}$ region by using a Nicolet $205 \times$ B spectrophotometer, equipped with a Data Station, at a spectral resolution of 1 
$\mathrm{cm}^{-1}$ and accumulations of 128 scans. $\zeta$-potential measurements were conducted in a Zetasizer Nano ZS (Malvern Instruments Ltd., Worcestershire, UK). Dried material was re-suspended in deionized water $(\mathrm{pH} 7)$ at a concentration of $5 \mu \mathrm{g} / \mathrm{mL}$ and measurements were performed at $25^{\circ} \mathrm{C}$. Organic and water contents were calculated from elemental analysis (FISONS, EA 1108 CHNS-O) and thermogravimetric (TGA) measurements (Mettler-Toledo TGA/SDTA851e).

\subsection{Materials stability and camptothecin release}

Material stability and non-specific drug release was monitored over CPT loaded samples in DMEM supplemented with 10\% fetal bovine serum (FBS) and 1\% antibiotic (streptomycin/penicillin), by incubating $1 \mathrm{mg} \mathrm{mL}^{-1}$ at $37^{\circ} \mathrm{C}$ (Thermomixer ${ }^{\circledR}, 1500 \mathrm{rpm}$ ) from 1 to $48 \mathrm{~h}$. Afterwards, samples were centrifuged $(21,100 \mathrm{G}, 15 \mathrm{~min})$, and the supernatant was treated with $500 \mu \mathrm{L}$ of $5 \%$ aqueous solution of trichloroacetic acid at $4{ }^{\circ} \mathrm{C}$ to precipitate serum proteins, which were separated after centrifugation $(6200 \mathrm{G}, 10 \mathrm{~min})$ prior to freeze-drying. In all cases, the residue was reconstituted with $2 \mathrm{~mL}$ of a methanol/ $\mathrm{HCl}$ $(95: 5 \mathrm{v} / \mathrm{v})$ solution. Then, CPT and/or CPT derivatives were quantified by fluorescence high performance liquid chromatography (HPLC-FL, $460 \mathrm{~nm}$ ). Experiments were done in triplicate. In addition, to study the influence of $\mathrm{pH}$ over CPT release, DMEM $\mathrm{pH}$ was adjusted in the range 3-5 by using $\mathrm{HCl}(0.1 \mathrm{M})$.

Besides, CPT total amount in every sample was determined by complete nanoMOF hydrolysis in alkaline medium $\left(1 \mathrm{mg} \mathrm{mL}^{-1}, \mathrm{NaOH} 0.03 \mathrm{M}\right)$ at $37{ }^{\circ} \mathrm{C}$ in a Thermomixer ${ }^{\circledR}$ equipment (1500 rpm). After 3h, samples were centrifuged (21,100 G, $15 \mathrm{~min})$, the supernatant freeze-dried and further dissolved with methanol/ $\mathrm{HCl}$ solution $(5 \%)$, and finally analyzed by HPLC-FL. Triplicate samples were measured in all cases. 


\subsection{Cell internalization assays}

NanoMOF uptake in HeLa cells was initially studied by colocalization experiments by laser confocal scanning microscopy (LCSM), Leica TCS-SP2-AOBS). 37500 cells/well (Lab-tek ${ }^{\circledR}$ 2-chambered \#1.0 borosilicate coverglass systems) were seeded and stabilized for $24 \mathrm{~h}$ in DMEM + F12 medium supplemented with 10\% FBS and 1\% antibiotic (streptomycin/penicillin) at $37{ }^{\circ} \mathrm{C}$ in $95 \%$ air and $5 \% \mathrm{CO}_{2}$ environment. Then, the growth medium was exchanged and cells with fresh medium were treated with $\mathrm{M} 1-\mathrm{RhB}$ and $\mathrm{M} 2-\mathrm{RhB}$, with final doses of 5 and $10 \mu \mathrm{g} \mathrm{mL}^{-1}$ of both materials, during $24 \mathrm{~h}$. After incubation, cells were repetitively washed with PBS to completely remove non-internalized particles. Before image acquisition cells were incubated at $37^{\circ} \mathrm{C}$ for 1 hour with 10 $\mu \mathrm{M}$ Lysotracker Green ${ }^{\circledR}$, fixed with $4 \%$ paraformaldehyde and incubated for 5 minutes with DAPI.

Moreover, quantitative cell internalization determinations were carried out by flow cytometry. For this purpose, HeLa cells were seeded in 12-well plates at a density of 75,000 cells/well and allowed to attach for $24 \mathrm{~h}$. Then, RhB-labeled nanomaterials (M1-RhB and $\mathrm{M} 2-\mathrm{RhB}$ ) were added to wells (in triplicate) at a final concentrations of 1, 5, 25 and $50 \mu \mathrm{g} \mathrm{mL} L^{-1}$ and maintained for 24 additional hours. After repetitively washing with PBS, adhered cells were trypsinized, carefully collected in DMEM medium and treated with $2 \mu \mathrm{L}$ of DRAQ $5^{\mathrm{TM}}$. Flow cytometric analyses were performed in a FC500 MPL Flow Cytometer (Beckman-Coulter). Data were analyzed and plotted for RhB and DRAQ $5^{\mathrm{TM}}$ in a two-way dot plot. Previously, calibration was carried out for two different gated regions: cells with no nanoparticles and DRAQ $5^{\mathrm{TM}}$ and cells with DRAQ $5^{\mathrm{TM}}$ and nanoparticles. All data were expressed as mean \pm standard deviation (SD). 


\subsection{Cytotoxicity study}

Fibroblast 3T3, HeLa and Neuroblastoma SH-SY5Y cells $\left(40,000\right.$ cell $\mathrm{mL}^{-1}, 20,000$ cells $\mathrm{mL}^{-1}$ and 50,000 cells $\mathrm{mL}^{-1}$, respectively) were seeded and stabilized for $24 \mathrm{~h}$ in DMEM (3T3 and HeLa) or DMEM + F12 (SH-SY5Y), supplemented with 10\% FBS and $1 \%$ antibiotic (streptomycin/penicillin) at $37{ }^{\circ} \mathrm{C}$ in $95 \%$ air and $5 \% \mathrm{CO}_{2}$ environment. Then, cells were treated with unloaded nanoMOFs, CPT loaded nanoMOFs or CPT (in DMSO), with final doses ranging from 0.0002 to $20 \mu \mathrm{g} \mathrm{mL}^{-1}$ in CPT equivalents during $72 \mathrm{~h}$. At the end of the incubation period, MTT (3-(4,5-dimethylthiazol-2-yl)2,5-diphenyltetrazolium bromide) solution in PBS was added at a final concentration of $1 \mathrm{mg} \mathrm{mL}^{-1}$ to the wells and $3 \mathrm{~h}$ later formazan crystals were dissolved in DMSO and spectrophotometrically measured at $595 \mathrm{~nm}$ (1681130 iMark ${ }^{\mathrm{TM}}$ Microplate Reader). $\mathrm{IC}_{50}$ calculation survival data were evaluated by nonlinear regression sigmoidal doseresponse (variable slope) curve-fitting using Prism 6.0 software (GraphPad, San Diego, CA). At least three independent experiments were performed for every sample, and each experiment was carried out by triplicate. All data were expressed as mean \pm standard error (SEM).

\section{Results}

CPT containing MOFs were prepared by post-synthetic modification of amine containing MIL-100(Fe) and MIL-101(Fe) materials. In a first step, MOFs were synthesized at the nanoscale with amine functionalized polycarboxylate ligands and iron (III). In parallel, prodrugs of CPT with two different linking groups were prepared by esterification. Then, in a second step CPT prodrugs were incorporated over MOF structure by amide bond formation or click chemistry. The different synthetic protocols used are summarized in Scheme 1. Moreover, Table 1 compiles the different samples obtained and their main physico-chemical properties. 


\subsection{Amine functionalized Iron (III) MOFs}

Two different metal-organic frameworks have been used as base material for the covalent and stable linking of camptothecin molecule. Iron (III) polycarboxylate materials MIL-101(Fe) and MIL-100(Fe) functionalized with amine groups were synthesized at the nanoscale by using solvothermal synthesis methodologies.

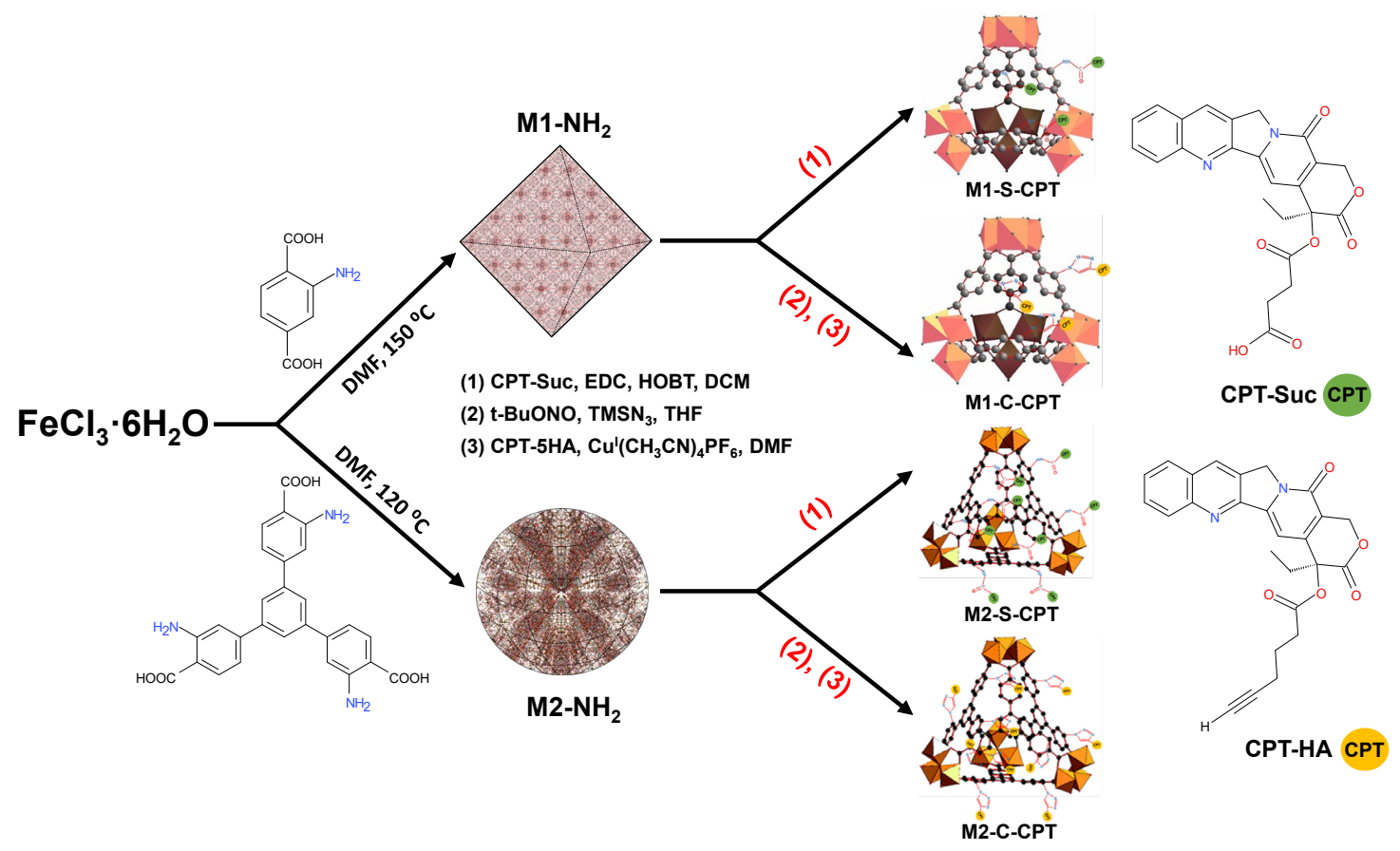

Scheme 1. Synthesis layout of CPT-loaded Fe (III) MOFs nanoparticles.

Table 1 Compositional and textural properties of the as-synthesized materials in the present work.

\begin{tabular}{|c|c|c|c|c|c|c|c|}
\hline \multirow[t]{2}{*}{ Sample } & \multirow[t]{2}{*}{ Composition } & \multirow[t]{2}{*}{$\mathrm{CPT}^{a}$ (wt. \%) } & \multirow[t]{2}{*}{ Size $(\mathbf{n m})^{b}$} & \multicolumn{3}{|c|}{ BET $^{c}$} & \multirow[t]{2}{*}{$\zeta$-potential (mV) } \\
\hline & & & & $\operatorname{Area}\left(m^{2} \cdot g^{-1}\right)$ & $V p\left(\mathrm{~cm}^{3} \cdot \mathrm{g}^{-1}\right)$ & Dp (nm) & \\
\hline $\mathrm{M} 1-\mathrm{NH}_{2}$ & Nano-MIL-101(Fe)-NH ${ }_{2}$ & - & $193 \pm 38$ & 1824 & 0.38 & 3.9 & +16.2 \\
\hline M1-S-CPT & Nano-MIL-101(Fe)-Suc-CPT & 17.6 & $189 \pm 61$ & 1254 & 0.16 & 3.6 & +6.4 \\
\hline M1-C-CPT & Nano-MIL-101(Fe)-Click-CPT & 18.0 & $194 \pm 81$ & 143 & 0.03 & 3.4 & +3.4 \\
\hline M1-A-CPT & Nano-MIL-101(Fe)-NH ${ }_{2}+\mathrm{CPT}$ & 6.2 & $189 \pm 85$ & 169 & 0.05 & 3.8 & +7.8 \\
\hline M1-RhB & Nano-MIL-101(Fe)-RhB & - & $185 \pm 56$ & 1325 & 0.14 & 3.8 & +9.4 \\
\hline $\mathrm{M} 2-\mathrm{NH}_{2}$ & Nano-MIL-100(Fe)-NH $\mathrm{NH}_{2}$ & - & $117 \pm 33$ & 88 & 0.09 & 7.2 & -31.5 \\
\hline M2-S-CPT & Nano-MIL-100(Fe)-Suc-CPT & 1.3 & $112 \pm 37$ & 71 & 0.07 & 3.5 & -27.0 \\
\hline M2-C-CPT & Nano-MIL-100(Fe)-Click-CPT & 9.2 & $132 \pm 51$ & 70 & 0.09 & 3.6 & -45.8 \\
\hline M2-A-CPT & Nano-MIL-100(Fe)-NH ${ }_{2}+\mathrm{CPT}$ & 0.9 & $98 \pm 28$ & 71 & 0.08 & 3.1 & -19.3 \\
\hline $\mathrm{M} 2-\mathrm{RhB}$ & Nano-MIL-100(Fe)-RhB & - & $111 \pm 38$ & 79 & 0.08 & 3.9 & -27.7 \\
\hline
\end{tabular}

${ }^{a}$ As determined by HPLC with fluorescence detection.

${ }^{b}$ As determined by the TEM study of single particles: mean \pm SD $(n \geq 200)$.

${ }^{c}$ As determined by nitrogen adsorption-desorption isotherms (BET-BJH method); Area $=$ Surface area; $\mathrm{Vp}=$ pore volume; Dp = pore diameter. 
In the case of $\mathrm{M} 1-\mathrm{NH}_{2}$, octahedral monodisperse nanoparticles of $193 \pm 38 \mathrm{~nm}$ average diameter were observed by TEM, in which the (111) planes of its structure could be appreciated with an interplanar distance of $5.1 \mathrm{~nm}$ (Fig. 1a) and the typical powder XRD pattern of these materials (Fig. 2 and Fig. S1). Nitrogen adsorption-desorption isotherms showed that $\mathrm{M} 1-\mathrm{NH}_{2}$ material has a huge external surface area $\left(>1800 \mathrm{~m}^{2} \mathrm{~g}^{-1}\right)$ and large pores of about $3.9 \mathrm{~nm}$ diameter (Table 1, Fig. S2), also reported by other authors [11], whereas elemental analysis revealed an amino group concentration of $3.6 \mathrm{mmol} \mathrm{g}^{-1}$, very close to the stoichiometric calculation $\left(3.8 \mathrm{mmol} \mathrm{g}^{-1}\right)$.

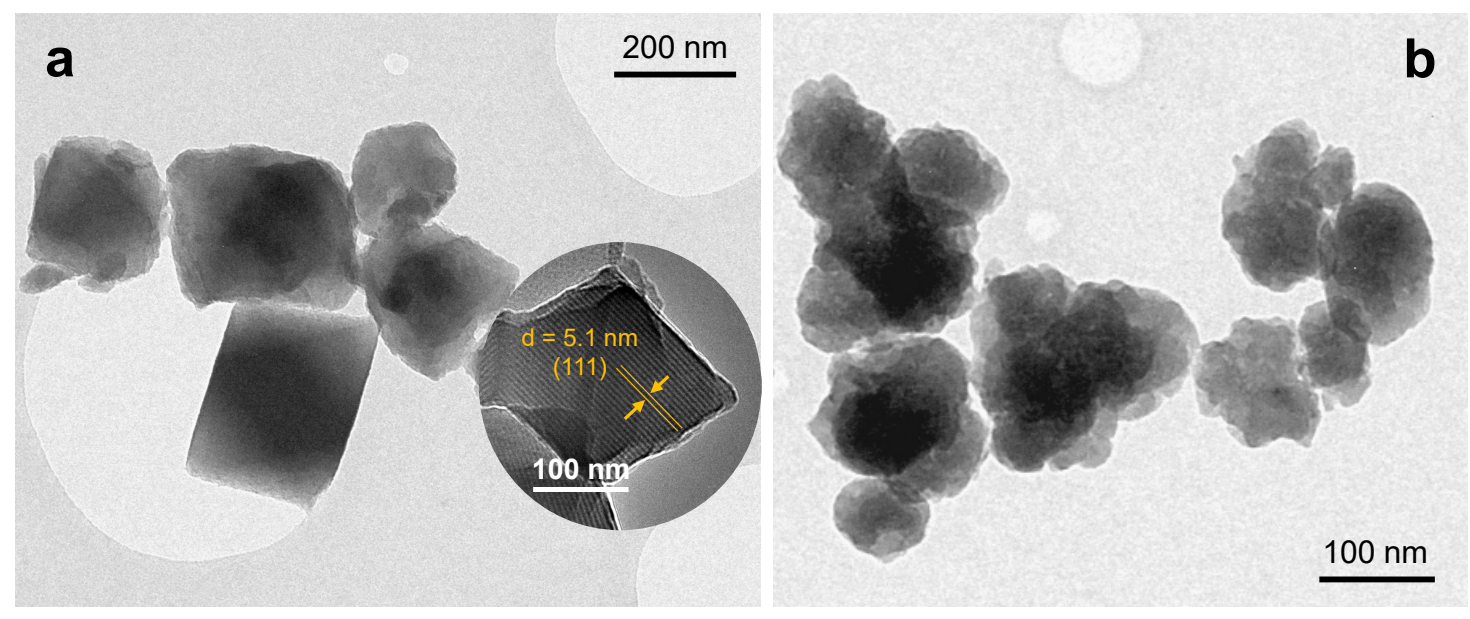

Fig. 1. Transmission electron microscopy micrographs of (a) $\mathrm{M} 1-\mathrm{NH}_{2}$ and (b) $\mathrm{M} 2-\mathrm{NH}_{2}$ nanoparticles.

In the case of $\mathrm{M} 2-\mathrm{NH}_{2}$ material we introduced acetic acid in the synthetic process to modulate crystal growth rate, as already shown for other MOF structures [12,32], obtaining monodispersed nanoparticles of about $117 \pm 33 \mathrm{~nm}$ average diameter, as determined by TEM measurements (Fig. 1b). However, with the use of BTB-NH 2 ligand with three primary amino groups per molecule in $\mathrm{M} 2-\mathrm{NH}_{2}$ synthesis coordination polymers with low crystallinity were obtained, as shown by XRD pattern (Fig. 2).

Unfortunately, BET area and pore volume are highly reduced in this material (Table 1 and Fig. S2), despite the large theoretical values [31]. This phenomenon has been attributed to the high cross-linking degree between the BTB- $\mathrm{NH}_{2}$ ligands and very large pore diameter $(7.2 \mathrm{~nm})$, as previously reported [30,31]. Also consistent with the multi- 
functionalized ligand used for the synthesis, this material presented a higher amino group concentration of $5.2 \mathrm{mmol} \mathrm{g}^{-1}$, whereas stoichiometric calculation gives $4.4 \mathrm{mmol}$ $\mathrm{g}^{-1}$. We assign such discrepancy to structural defects and some BTB-NH 2 ligand adsorption.

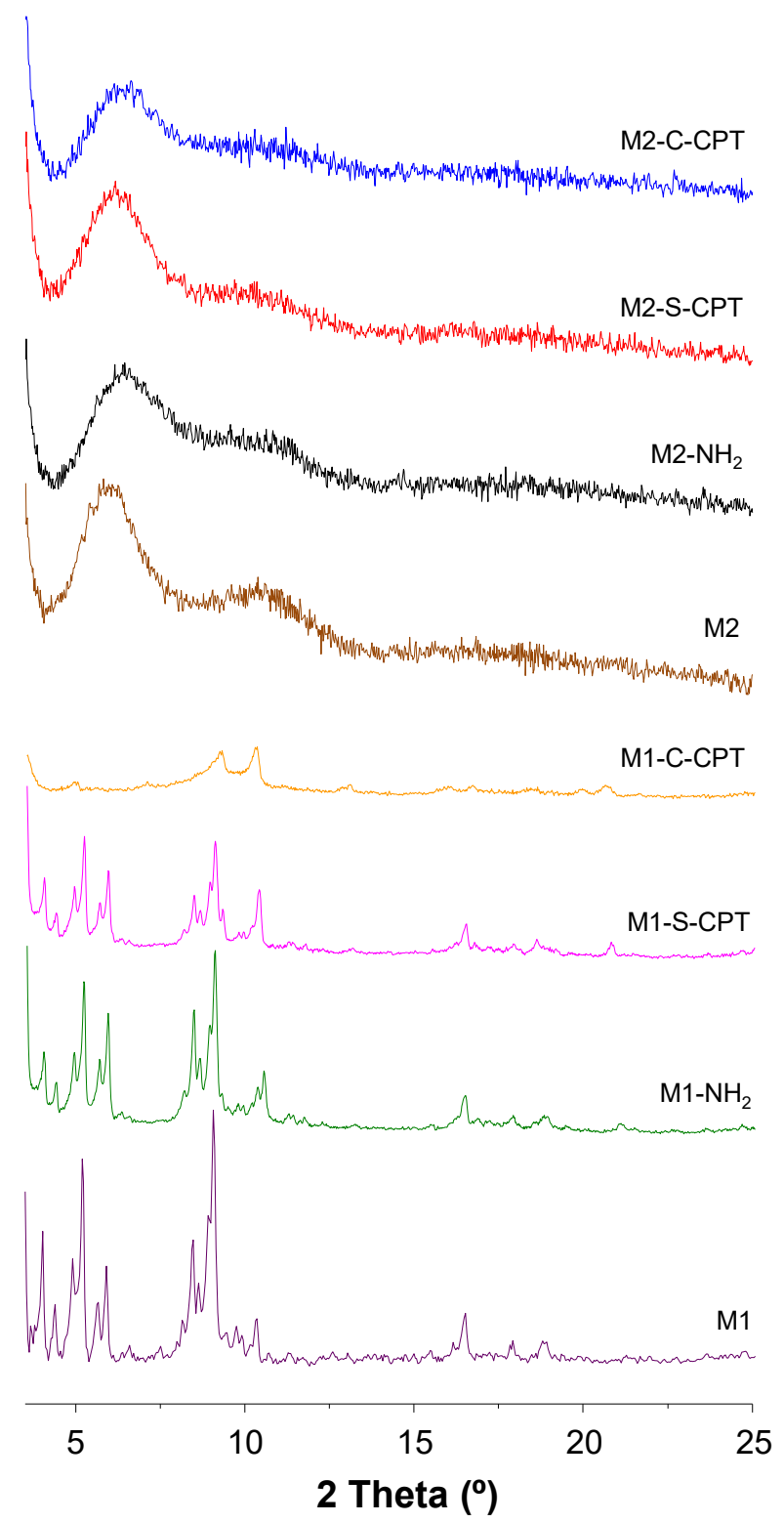

Fig. 2. Powder X-ray diffraction (PXRD) patterns of as-made $\mathrm{M} 1-\mathrm{NH}_{2}$ and its $\mathrm{CPT}$ derivatives and asmade $\mathrm{M} 2-\mathrm{NH}_{2}$ and its $\mathrm{CPT}$-derivatives. 


\subsection{Incorporation of camptothecin}

As commented above, for CPT incorporation over amine functionalized MOFs, the drug was previously esterified with a linker chain. Subsequently, these CPT prodrugs were conjugated with nanoMOF primary amine groups through amide bond or click chemistry. No morphology changes were associated to post-synthetic treatments (Fig. S3).

In the first case, the amide bond is performed between amino groups and the terminal carboxylic acid of CPT-Suc. This approach allowed us to incorporate almost $18 \mathrm{wt} \%$ $\mathrm{CPT}$ in $\mathrm{M} 1-\mathrm{NH}_{2}$, which is consistent with the high surface area and crystallinity of this material. Actually, a significant reduction of surface area and pore diameter (Table 1) was noticed, which is associated with some pore blocking by conjugated CPT, although no change in crystallinity was observed according to the XRD pattern (Fig. 2, M1-SCPT). Conversely, M2-NH 2 sample only bonded $1 \mathrm{wt} \% \mathrm{CPT}$ by the same procedure. We attribute this reduced reactivity and small drug loading capability to the hindered accessibility of amino groups in a MOF structure with low crystallinity and surface area, as already shown by other authors [37-39].

Amide bond successful formation between CPT-Suc and M1-NH 2 was assessed by two wide and broad stretching N-H vibration bands at $3460 \mathrm{~cm}^{-1}$ and $3362 \mathrm{~cm}^{-1}$ in the FTIR spectrum [40]. In addition, the low intensity band at $1745 \mathrm{~cm}^{-1}$ corresponds to stretching vibration of CPT lactone carbonyl group $(v \mathrm{C} 20=\mathrm{O} 22)$ [41] (Fig. 3). This band is not evident in M2-S-CPT FTIR spectrum, due to the low CPT quantity incorporated.

As a second strategy for CPT covalent bonding to amine functionalized nanoMOFs we took advantage of click chemistry [42], by using CPT-HA prodrug. Firstly, we reacted amino containing MOF nanoparticles with t-BuONO and $\mathrm{TMSN}_{3}$ in order to quantitatively convert $-\mathrm{NH}_{2}$ into azido $\left(-\mathrm{N}_{3}\right)$ groups, and then we completed the [3+2] coupling with CPT-HA addition. 
By this protocol we incorporated $18 \mathrm{wt} \% \mathrm{CPT}$ in $\mathrm{M} 1-\mathrm{C}-\mathrm{CPT}$ and $9 \mathrm{wt} \% \mathrm{CPT}$ in M2-CCPT. The superior reactive efficacy of the click chemistry process is reflected by the high CPT loading obtained onto $\mathrm{M} 2-\mathrm{NH}_{2}$ sample, despite of the commented lower accessibility of amino groups. Unfortunately, M1-N 3 product suffered a significant loss of crystallinity (Fig. S4) and, consequently, a sharp surface area drop (Table 1). This effect was not so apparent for M2- $\mathrm{N}_{3}$, due to the lower crystallinity and surface area of M2$\mathrm{NH}_{2}$ sample. (Fig. S4, Table 1).

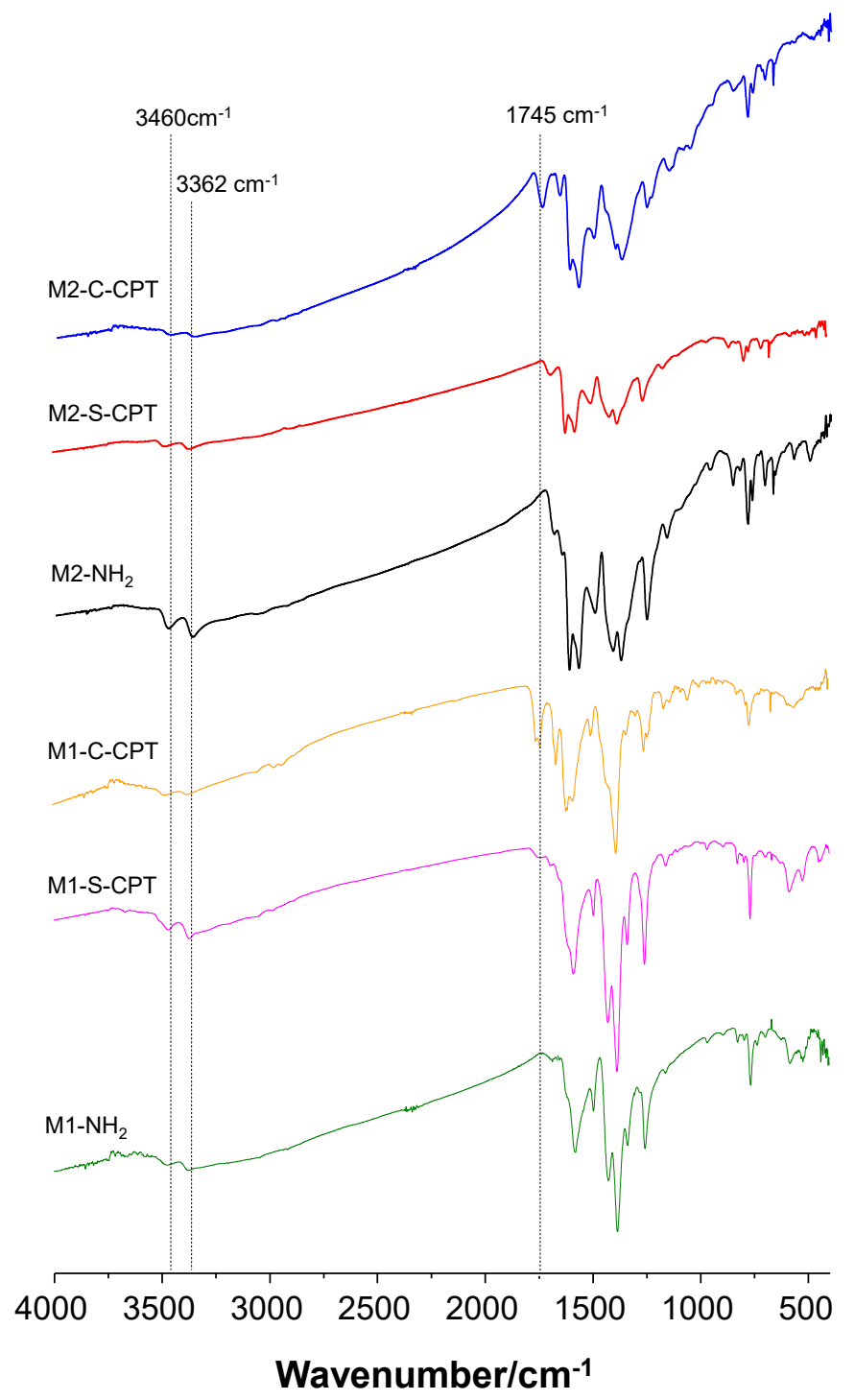

Fig. 3. FTIR spectra of the as synthetized $\mathrm{M} 1-\mathrm{NH}_{2}$ and its CPT-loaded derivatives and $\mathrm{M} 2-\mathrm{NH}_{2}$ and its CPT-loaded derivatives, showing the principal vibrational bands.

Azide formation in nanoMOFs was monitored by the asymmetric stretching band due to azide group at $2120 \mathrm{~cm}^{-1}$ in the FTIR spectrum [43]. This band was intense in $\mathrm{M} 1-\mathrm{N}_{3}$ 
and M2-N3 samples (Fig. S5), and was fully suppressed after completing alkyne addition. Also, CPT incorporation was proven by carbonyl group band at $1750 \mathrm{~cm}^{-1}$ (Fig. 3) [41].

For the sake of comparison, we also loaded CPT by physical adsorption into amine functionalized nanoMOFs. In this sense, samples M1-A-CPT and M2-A-CPT, incorporated, respectively, 6 and $1 \mathrm{wt} \% \mathrm{CPT}$, which is consistent with the observed surface area differences between these samples. No visible change in crystallinity was detected (Fig. S6), but $\mathrm{M} 1-\mathrm{NH}_{2}$ suffered an important surface area reduction, due to internal pore blocking (Table 1, Fig. S7).

\subsection{Materials stability study and influence of $p H$}

CPT loaded nanoMOFs may suffer of non-specific release in physiological conditions, mostly by direct hydrolysis of the ester bond between drug and vehicle, then releasing free CPT, or by material structure disintegration, which releases different $\mathrm{CPT}+$ lateral chain fragments. In this context, the stability of nanoMOF-CPT conjugates was tested in DMEM (pH 7.4) supplemented with $10 \% \mathrm{FBS}$ and $1 \%$ antibiotic at $37{ }^{\circ} \mathrm{C}$ with shaking (1500 rpm, Thermomixer®).

M1-S-CPT and M1-C-CPT samples discharged at $\mathrm{pH} 7.4$, respectively, 8 and $12 \%$ total CPT in the first hour, and no further release took place up to $48 \mathrm{~h}$ (Fig. 4a,b). This release pattern corresponded mostly to physically adsorbed CPT prodrugs (CPT-Suc or CPTHA, as detected by HPLC-FL), due to the large surface area and highly ordered porosity of M1-NH 2 material. Also, a very small quantity of free CPT was also detected, probably caused by prodrug hydrolysis. In a further try to fully eliminate the adsorbed CPT prodrug from particle surface, we washed out as-synthesized M1-S-CPT and M1-C-CPT samples with SDS and Tween-20 surfactants. Unfortunately, this treatments are quite 
aggressive to the structure of functionalized MOF, and in all cases this was seriously altered, as observed in the XRD patterns (data not shown).
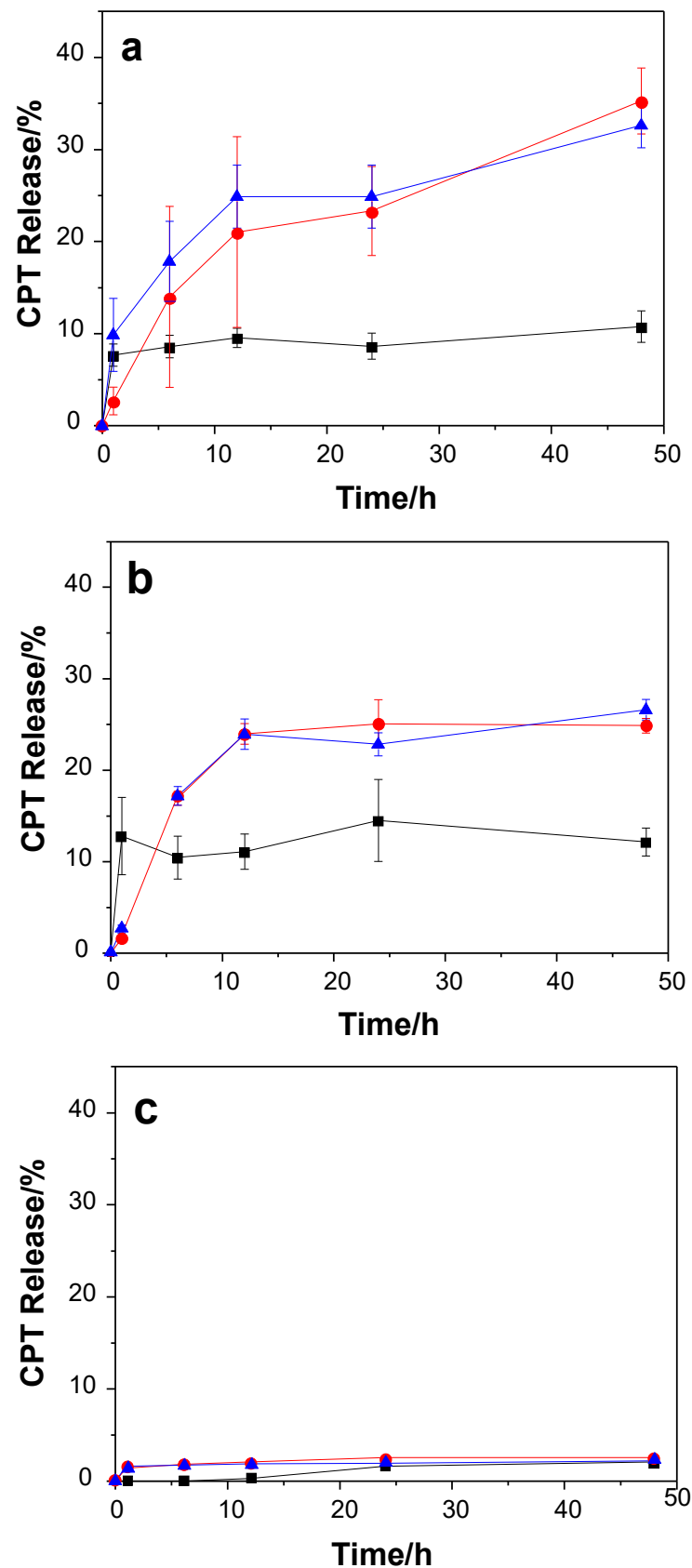

Fig. 4. In vitro stability and CPT release profiles of M1-S-CPT (a) M1-C-CPT (b) and M2-C-CPT (c) under physiological and acid $\mathrm{pH}$. CPT release percentage was calculated with regards incorporated drug total quantity (as determined by complete nanoMOF hydrolysis in alkaline medium). Legend: $\mathrm{pH}=7.4$ $(\boldsymbol{\square}), \mathrm{pH}=5.00(\bullet), \mathrm{pH}=3.00(\boldsymbol{\Delta})$. CPT release data are expressed as the mean $\pm \mathrm{SD}(\mathrm{n}=3)$.

Conversely, covalently linked CPT remained stable in physiological conditions. This initial CPT burst release was not observed over M2-C-CPT sample, as its lower crystallinity and BET area prevent strong physical adsorption of CPT derivatives, with non- 
specific release limited to $2 \%$ (Fig. 4c). M2-S-CPT was not considered for this study due to its lower CPT content.

However, CPT nanoplatforms prepared by physical adsorption revealed very unstable in cell culture medium and, for instance, M1-A-CPT sample discharged almost 50\% of its therapeutic load in the first 6 hours, and completed the process in $24 \mathrm{~h}$ (Fig. S8).

No release measurement was taken from M2-A-CPT by same rationale than M2-S-CPT. Besides, some MOFs based on iron (III) carboxylates are sensitive to moderate acid $\mathrm{pH}$, as that of lysosomes, which accelerates their degradation rate. This is due to organic linkers protonation and loss of $\mathrm{Fe}^{3+/ 2+}$ species, which leads to structure collapse. In our case, after cell internalization of MOF nanoparticles and endosomal-lysosomal trafficking, this can release different CPT derivatives to the cytosolic medium, where specific enzymes hydrolyze the ester bond between CPT and the linker chain $[13,44,45]$. In this context, we subjected CPT containing samples M1-S-CPT, M1-C-CPT and M2-C-CPT to stability experiments in acidified DMEM medium ( $\mathrm{pH} 5.0$ or $\mathrm{pH} 3.0)$ supplemented with $10 \%$ FBS and $1 \%$ antibiotic at $37^{\circ} \mathrm{C}$ with shaking (1500 rpm, Thermomixer $\left.{ }^{\circledR}\right)$. Results (Fig. 4) showed an important increase of CPT release for MIL-101(Fe) based DDSs at $\mathrm{pH} 5$, estimated over 35\% for M1-S-CPT and 23\% for M1-C-CPT at $48 \mathrm{~h}$, and no additional CPT discharge was achieved for $\mathrm{pH}$ 3. Most of this CPT was released as fragments from MOF structure degradation. They were identified by UPLC-MS/MS with the general formula CPT-Linker-Ligand and are presented in the Supporting Information (compounds $\mathbf{1}$ and $\mathbf{1}^{\prime}$ in Fig. S9) together with their corresponding release curves (Fig. S10). Moreover, significant quantities of physically adsorbed CPT prodrugs (CPTSuc or CPT-HA) were also released, and a small quantity of free CPT was also detected, resulting of the promoted ester bond hydrolysis in acid medium. 
Conversely, M2-C-CPT was very little affected by acid $\mathrm{pH}$. As commented before, the lower crystallinity and surface area of MIL100(Fe) based materials precludes diffusion inside the framework, which minimizes the effect of medium conditions over structure components.

\subsection{Cell internalization study}

Cell uptake studies over HeLa cell line were carried out with RhB derivatives of Iron (III) nanoMOFs. These incorporated about $1 \%$ of the fluorochrome with no significant changes in crystallinity (data not shown), and a slight reduction of surface area attributed to some pore blocking by the organic ligand (Table 1). Flow cytometry analysis showed strong differences in cell internalization between $\mathrm{M} 1-\mathrm{RhB}$ and $\mathrm{M} 2-\mathrm{RhB}$ at low particle concentration (1-5 $\mu \mathrm{g} \mathrm{mL}^{-1}$, Fig. 5 and Table 2). For instance, at $5 \mu \mathrm{g} \mathrm{mL} \mathrm{L}^{-1} \mathrm{M} 1-\mathrm{RhB}$ was loaded by $95.9 \pm 1.0 \%$, whereas only $20.3 \pm 13.0 \% \mathrm{M} 2-\mathrm{RhB}$ was uptake. We arraign this effect to the high negative $\zeta$-potential of $\mathrm{M} 2-\mathrm{NH}_{2}$ and derivatives in physiological medium (Table 1), which limits intracellular diffusion due to electrostatic repulsion with cell membrane [44]. Conversely, $\mathrm{M} 1-\mathrm{NH}_{2}$ derived materials showed $\zeta$-potential positive (Table 1), favoring the cell internalization process.

Table 2 Flow cytometry results over HeLa cells incubated with different particle concentration of $\mathrm{RhB}$-functionalized samples. Data corresponding to cell internalization percentage are expressed as mean $\pm \mathrm{SD}(\mathrm{n}=3)$.

\begin{tabular}{|c|c|c|c|c|}
\hline Sample & $1 \mu \mathrm{g} \mathrm{mL}^{-1}(\%)$ & $5 \mu \mathrm{g} \mathrm{mL} L^{-1}(\%)$ & $25 \mu \mathrm{g} \mathrm{mL}^{-1}(\%)$ & $50 \mu \mathrm{g} \mathrm{mL}^{-1}(\%)$ \\
\hline M1-RhB & $81.7 \pm 11.5$ & $95.9 \pm 1.0$ & $98.4 \pm 0.9$ & $100 \pm 0.004$ \\
\hline $\mathrm{M} 2-\mathrm{RhB}$ & $22.1 \pm 28.9$ & $20.3 \pm 13.0$ & $80.5 \pm 3.8$ & $99.98 \pm 0.033$ \\
\hline
\end{tabular}

Additional cell uptake studies were done by CLSM. HeLa cells were incubated with $\mathrm{M} 1-\mathrm{RhB}$ or M2-RhB sample in the range $5-10 \mu \mathrm{g} \mathrm{mL} \mathrm{L}^{-1}$ for 24 hours, and the internalized nanoparticles were monitored by colocalization experiments. In the case of $\mathrm{M} 1-\mathrm{RhB}$, successful material internalization by HeLa cells was clearly observed, with almost 
$100 \%$ colocalization of nanoparticles and lysosomes (Fig. 5d-f). On the contrary, M2-

$\mathrm{RhB}$ underwent lower cell internalization (estimated over 35\%, Fig. 5g-i), which is consistent with flow cytometry results.
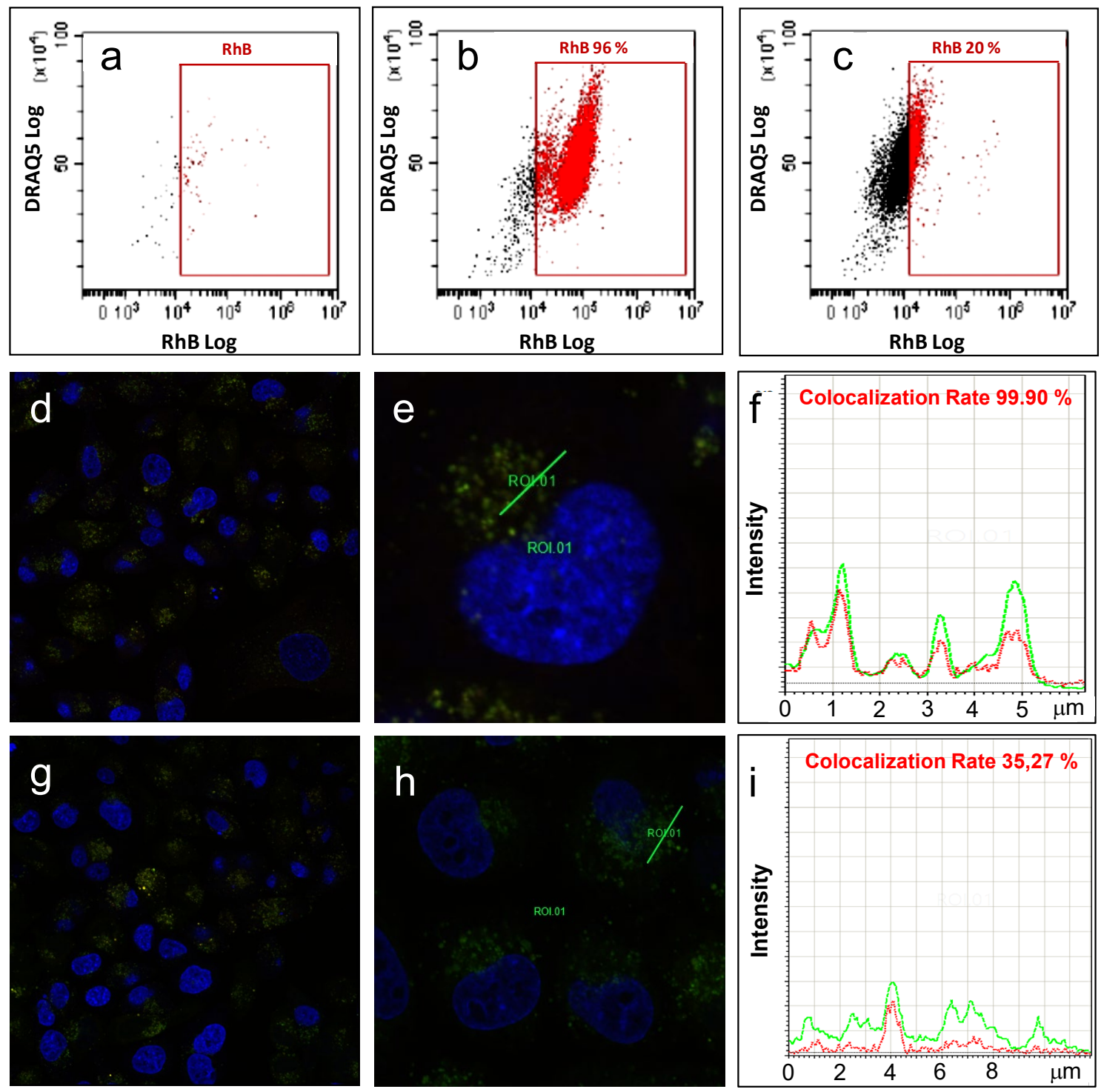

Fig. 5. Representative graphics of flow cytometry assays for HeLa cells incubated $24 \mathrm{~h}$ with $5 \mu \mathrm{g} \mathrm{mL} \mathrm{m}^{-1}$ of RhB loaded MOFs and after DRAQ5 staining. Two-way plots were obtained as shown, (a) HeLa cells. (b) M1-RhB. (c) M2-RhB. Two different gated regions were quantified: cells with no nanoparticles (black dots) and cells with nanoparticles (red dots). Experiments were performed by using triplicate samples. Colocalization studies are presented for M1-RhB (d-f) and M2-RhB (g-i) at $10 \mu \mathrm{g} \mathrm{mL} \mathrm{L}^{-1}$. Images $\mathrm{d}$ and $\mathrm{g}$ show a general view of the cells after being incubated with the materials, which are marked in red (RhB, nanoparticles in cytosol), lysotracker ${ }^{\circledR}$ (green, acidic organelles) and DAPI (blue, cell nuclei). Images e and $\mathrm{h}$ present details of these pictures showing colocalization of $\mathrm{M} 1-\mathrm{RhB}$ and $\mathrm{M} 2-\mathrm{RhB}$ nanoparticles with acidic organelles (yellow dots). Green lines indicate the regions of interest (ROI) selected for signal intensity plots (f and i). 


\subsection{Cytotoxicity study}

Cytotoxic activity by MTT assay was validated solely over $\mathrm{M} 1-\mathrm{NH}_{2}$ derivatives with CPT (M1-S-CPT and M1-C-CPT). No further in vitro study was done over M2-C-CPT sample, due to its lower CPT content and limited intracellular diffusion. Also, samples with physically adsorbed CPT (e.g., M1-A-CPT) are not appropriate for in vitro or in vivo studies, as they are not able to impose any controlled release over the drug.

Firstly we tested the biocompatibility of the non-loaded material (M1-NH2) over HeLa and SH-SY5Y cell lines at the corresponding nanoparticle concentration range. Results (Fig. 6) indicate that even at the highest particle loading $\left(100 \mu \mathrm{g} \mathrm{mL}^{-1}\right)$, the relative cell viability was above $80 \%$. Despite MTT testing limitations for accurate cell viability determination, these results correspond to an acceptable biocompatibility profile [46]. Subsequently, a dose range of $0.001-20 \mu \mathrm{gL}^{-1}$ of equivalent CPT was used with M1-SCPT and M1-C-CPT samples. For the purpose of comparison, CPT cytotoxic activity was also determined (Fig. S11). Both tested materials presented similar half-maximal inhibitory concentration ( $\mathrm{IC}_{50}$ ) values, which is consistent with their similar CPT load. However, cytotoxic activity was lower than free CPT (Table 3). In this sense, it have been shown that CPT esterification over nanoparticles can limit enzymatic ester cleavage at the cytosol, precluding complete release and limiting the cytotoxic activity $[28,45]$.

Moreover, in order to state an estimation of the possible secondary effects that these formulations could have on healthy tissue, we have tested free CPT and M1-S-CPT and M1-C-CPT samples in normal fibroblasts 3T3. The obtained results are presented in Table 3 and Fig. S12. It is noticeable that the fibroblast cell line is very much resistant to the M1 nanomedicines than the cancer cells, showing $\mathrm{IC}_{50}$ values over two orders 
higher for both materials. We attribute these differences to the promoted particle endocytosis inherent to the cancer cell lines [47].
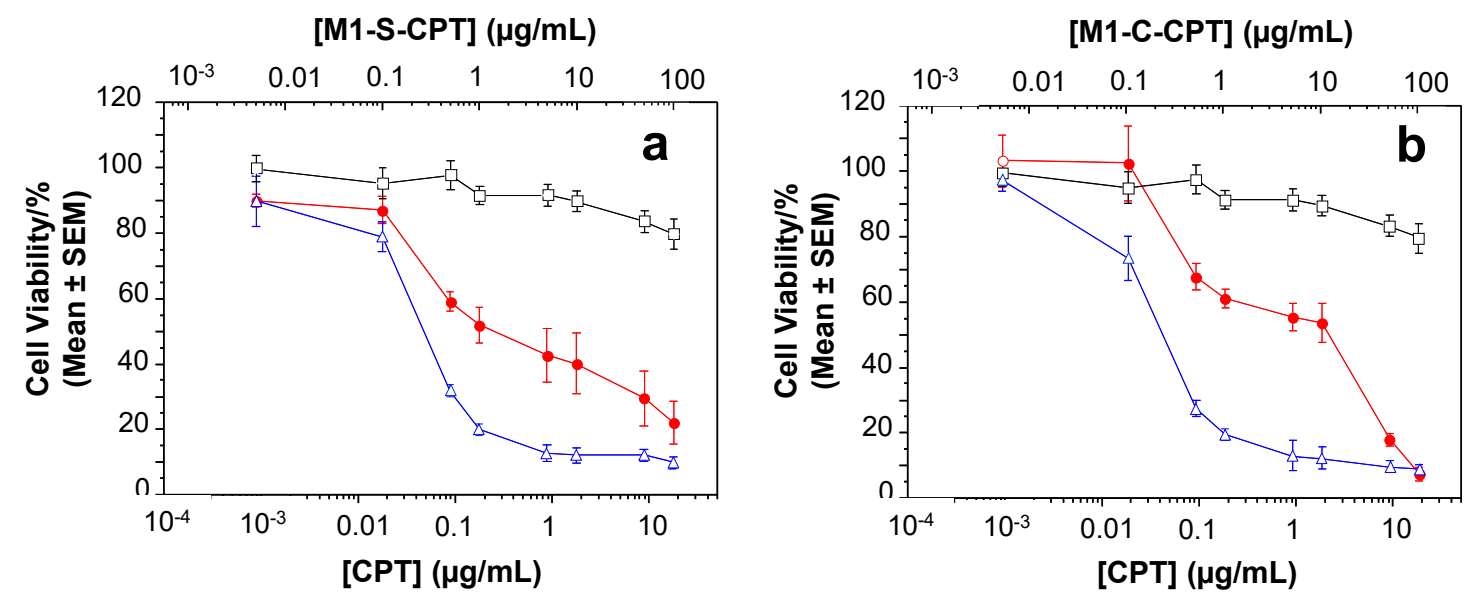

Fig. 6. In vitro MTT cell viability assays in $\mathrm{HeLa}(\bullet)$ and neuroblastoma SH-SY5Y ( $\Delta$ ) cell lines. (a) M1S-CPT. (b) M1-C-CPT. Sample concentration is referred to CPT equivalent (lower scale). Non-loaded material $\left(\mathrm{M} 1-\mathrm{NH}_{2}\right)$ was tested over HeLa cell line $(\square)$, and its concentration is referred at the upper scale. Cell viability data are expressed as mean $\pm \operatorname{SEM}(n=3)$.

Table 3 IC $_{50}$ values for MIL101-derivatives over HeLa, neuroblastoma and fibroblast 3T3 cell lines.

\begin{tabular}{lccc}
\hline Cell line & CPT & M1-S-CPT $^{\mathbf{a}}$ & M1-C-CPT $^{\mathbf{a}}$ \\
\hline HeLa & $0.003 \pm 0.001$ & $0.078 \pm 0.016$ & $0.063 \pm 0.015$ \\
Neuroblastoma (SH-SY5Y) & $9.77 \cdot 10^{-4} \pm 3.7 \cdot 10^{-5}$ & $0.040 \pm 3.2 \cdot 10^{-3}$ & $0.029 \pm 2.5 \cdot 10^{-3}$ \\
Fibroblast 3T3 & $0.009 \pm 0.003$ & $3.794 \pm 0.459$ & $6.393 \pm 0.773$ \\
\hline
\end{tabular}

${ }^{a}$ Each value indicates the mean $\pm \operatorname{SEM}(\mu \mathrm{g} / \mathrm{mL})$. All the experiments were carried out in triplicate.

\section{Discussion}

CPT has been covalently conjugated over different nanoplatforms, like cyclodextrins [48] or silica nanoparticles [45]. However, none of these supports is able to incorporate quantities above $10 \%$. The introduction of CPT onto metal-organic frameworks by covalent bonding has allowed achieving a superior drug loading (up to $18 \%$ ). We have found that material crystallinity and surface area determine the accessibility to amine groups and, consequently, CPT loading and CPT release. Moreover, such dramatic differences between MIL-101(Fe) and MIL-100(Fe) structures may be due to structural 
larger cages occupation, selective in the case of MIL-100(Fe), or complete in MIL$101(\mathrm{Fe})[2]$.

For CPT incorporation into amine-derivatized MOFs the drug is previously esterified with a linker chain, which may be linked over the primary amine groups by amide bond or click chemistry. No significant differences are noticeable for $\mathrm{M} 1-\mathrm{NH}_{2}$, which is consistent with a drug loading level close to material maximum capacity. However, the superior reactive efficacy of the click chemistry process brings a significant improvement in CPT incorporation on the lower surface area M2-NH2 sample [42].

These materials present good stability in physiological conditions, and no discharge of covalently conjugated drug is observed at $\mathrm{pH} 7.4$, although there is some initial release of physically adsorbed species, mostly in $\mathrm{M} 1-\mathrm{NH}_{2}$ derivatives, as its high surface area promotes this action. Conversely, samples obtained by single physical adsorption of $\mathrm{CPT}$ into the pores of $\mathrm{M} 1-\mathrm{NH}_{2}$ or $\mathrm{M} 2-\mathrm{NH}_{2}$ structures are unacceptable as DDSs, as they are not able to impose any specific drug discharge mechanism, losing more than $50 \%$ of their therapeutic load at the first stages of the process by non-specific release.

Conversely, the release profile for covalent conjugates of CPT with MIL-101(Fe) structure changes dramatically at acid $\mathrm{pH}$. Here, it must be taken into account that after cell uptake, the endosomolytic trafficking (lysosomal lumen's $\mathrm{pH} 4.5-5$ [49]) promotes drug discharge for acid-responsive systems. In this context, we have found at $\mathrm{pH} 5$ an increase in CPT release for MIL-101(Fe)-based DDSs of 2 to 4 fold with regards physiological $\mathrm{pH}$. Actually, most of the recent studies about $\mathrm{pH}$-sensitive MOFs for drug controlled release have been carried out over ZIF materials (mainly ZIF-8), due to the high sensitivity of imidazole ring to acidic conditions [50,51]. Also, other functional MOF structures containing borate units [52], phosphate [53] or polycarboxylic ligands [54,55] are prone to protonation and framework disassembly in acidic conditions. In the case of M1- 
S-CPT and M1-C-CPT samples approach, acid pH promotes carboxylate groups protonation, leading to loss of iron species and framework collapse. As a result, CPT is mostly release coupled to the corresponding structural ligand. Such previous digestion of MIL$101(\mathrm{Fe})$ structure by lysosomal activity is expected to pave the way for improved CPT release through ester hydrolysis at the cytosol by specific carboxylases. On the contrary, it has been reported that MIL-100(Fe) structure degradation under acid $\mathrm{pH}$ is very gradual and uncompleted [55], as the low crystallinity and surface area hinder internal diffusion and, in that sense, M2-C-CPT material showed little additional drug release with regards physiological $\mathrm{pH}$.

We have found significant differences in cell internalization between CPT loaded M1$\mathrm{NH}_{2}$ and M2- $\mathrm{NH}_{2}$ materials, both in flow cytometry and CLSM studies. On one hand, It must be taken into account that the positive charge of MIL-101(Fe) structure favors a strong opsonization process with serum proteins in cell culture medium, resulting in protein corona formation and, as a consequence, the endocytosis activity is highly promoted [56]. On the other hand, the very negative $\zeta$-potential of MIL-100(Fe) derivatives contributes to colloidal stability in physiological medium [56,57], but limits cell uptake due to electrostatic repulsion over cell membrane [58]. Such limited intracellular diffusion, gathered to the lower CPT loading achieved in $\mathrm{M} 2-\mathrm{NH}_{2}$ sample, prompted us to preclude MIL-100(Fe) based DDSs from further in vitro studies.

The biological activity of the novel CPT conjugates with amine functionalized MIL101(Fe) nanoparticles was tested over HeLa and neuroblastoma cell lines, showing less cytotoxicity that CPT, with $\mathrm{IC}_{50}$ values over 1 order higher than the free drug. This is not surprising, as the expected mechanism of intracellular drug release (20-O-ester bond hydrolysis by cytosolic carboxylases after cell uptake) is affected for some steric restrictions that forbid a complete release process. Actually, comparable limitations for 
complete intracellular release of CPT and lower $\mathrm{IC}_{50}$ values are reported in other DDSs where drug is covalently linked to the carrier $[45,48,59]$. However, CPT stabilization on MOF pores ensures that drug is not released in circulation and that its activation is only possible when nanoparticles are internalized into tumor cells. In this sense, the high CPT loading capability of MIL-101(Fe) material provides high cytotoxic activity even at low dose, and stimuli-responsive intracellular drug discharge, due to the high sensitivity of these DDSs to acid $\mathrm{pH}$, which are desired properties for in vivo administration of pharmaceutical forms.

Furthermore, the possible effect of M1-S-CPT and M1-C-CPT on healthy tissues may be roughly estimated by testing them in normal cell cultures. For this sake, we investigated their cytotoxicity over fibroblasts $3 \mathrm{~T} 3$. This cell line showed clearly higher resistance to the MIL-101(Fe) nanomedicines than cancer cells, with IC50 values over 2 order higher than HeLa and neuroblastoma, which we explain by the promoted particle endocytosis inherent to the cancer cell lines. It must be taken into account that the endocytosis is a multicomponent process entailing selective packaging of cell-surface proteins (e.g., cytokines receptors and adhesion components) in cytoplasmic vesicles (endosomes), which is enhanced and skewed in cancer cells [47]. In brief, that means that these nanomedicines are able to impose stronger cytotoxicity against the malign cells than normal cells, even when using no targeting device.

\section{Conclusions}

Although MOFs are promising structures for CPT delivery due to their tailorable porosity and easy functionalization [2], very few works have reported on the use of these materials for CPT loading, always through in situ trapping or via post-synthetic adsorption [28]. In this context, we here present novel DDSs based in amine functionalized MIL-100(Fe) and MIL-101(Fe) nanoMOFs with covalently bonded CPT, which are able 
to achieve efficient delivery to cancer cells and selective intracellular drug discharge. For this purpose, we have esterified CPT to different linker chains that are conjugated to MOF structure amine groups by amidation or click chemistry reaction. The resulting CPT nanoplatforms are able to incorporate almost $20 \%$ of this molecule and show high stability at physiological $\mathrm{pH}$, without unspecific release of the covalently coupled drug. Furthermore, CPT loaded MIL-101(Fe) derivatives present improved cell internalization due to their positive $\zeta$-potential, and a strong response to acid $\mathrm{pH}$, increasing drug discharge over 2 to 4 fold at $\mathrm{pH} 5$, which boost intracellular release by endosomolytic activity. Overall, these nanoMOFs constitute an appropriate vehicle for the safe delivery to cancer cells of the very cytotoxic CPT molecule with straightforward potential for in vivo application, as they allow reducing the therapeutic dose and minimize drug secondary effects.

\section{Acknowledgements}

Financial support of the Spanish Ministry of Economy and Competitiveness (projects TEC2016-80976-R and SEV-2016-0683) is gratefully acknowledged. A.C.G. thanks the

La Caixa Foundation for a Ph.D. scholarship. We fully appreciate the assistance of the Electron Microscopy Service of the Universitat Politècnica de València.

\section{References}

[1] B. Louage, O. De Wever, W.E. Hennink, B.G. De Geest, Developments and future clinical outlook of taxane nanomedicines, J. Control. Release. 253 (2017) 137-152. doi:10.1016/j.jconrel.2017.03.027.

[2] P. Horcajada, C. Serre, M. Vallet-Regí, M. Sebban, F. Taulelle, G. Férey, Metal-organic frameworks as efficient materials for drug delivery, Angew. Chemie - Int. Ed. 45 (2006) 5974-5978. doi:10.1002/anie.200601878.

[3] A. Baeza, D. Ruiz-Molina, M. Vallet-Regí, Recent advances in porous 
nanoparticles for drug delivery in antitumoral applications: inorganic nanoparticles and nanoscale metal-organic frameworks, Expert Opin. Drug Deliv. 5247 (2016) 1-14. doi:10.1080/17425247.2016.1229298.

[4] M. Ibrahim, R. Sabouni, G. Husseini, Anti-cancer drug delivery using metal organic frameworks (MOFs), Curr. Med. Chem. 24 (2017) 193-214. doi:10.2174/0929867323666160926151216.

[5] J. Jiang, Y. Zhao, O.M. Yaghi, Covalent chemistry beyond molecules, J. Am. Chem. Soc. 138 (2016) 3255-3265. doi:10.1021/jacs.5b10666.

[6] Z. Liu, L. Lv, Y. He, Y. Feng, An anionic metal-organic framework constructed from a triazole-functionalized diisophthalate featuring hierarchical cages for selective adsorptive $\mathrm{C}_{2} \mathrm{H}_{2} / \mathrm{CH}_{4}$ and $\mathrm{CO}_{2} / \mathrm{CH}_{4}$ separation, CrystEngComm. 19 (2017) 2795-2801. doi:10.1039/C7CE00661F.

[7] V.L. Rechac, F.G. Cirujano, A. Corma, F.X. Llabrés i Xamena, Diastereoselective synthesis of pyranoquinolines on Zirconium-containing UiO66 metal-organic frameworks, Eur. J. Inorg. Chem. (2016) 4512-4516. doi:10.1002/ejic.201600372.

[8] R. Medishetty, V. Nalla, L. Nemec, S. Henke, D. Mayer, H. Sun, K. Reuter, R.A. Fischer, A new class of lasing materials: intrinsic stimulated emission from nonlinear optically active metal-organic frameworks, Adv. Mater. 29 (2017) 17. doi:10.1002/adma.201605637.

[9] Z. Qi, L. Wang, Q. You, Y. Chen, PA-Tb-Cu MOF as luminescent nanoenzyme for catalytic assay of hydrogen peroxide, Biosens. Bioelectron. 96 (2017) 227232. doi:10.1016/j.bios.2017.05.013.

[10] J. Della Rocca, W. Lin, Nanoscale metal-organic frameworks: magnetic 
resonance imaging contrast agents and beyond, Eur. J. Inorg. Chem. (2010) 3725-3734. doi:10.1002/ejic.201000496.

[11] P. Horcajada, T. Chalati, C. Serre, B. Gillet, C. Sebrie, T. Baati, J.F. Eubank, D. Heurtaux, P. Clayette, C. Kreuz, J. Chang, Y.K. Hwang, V. Marsaud, P. Bories, L. Cynober, S. Gil, G. Ferey, P. Couvreur, R. Gref, Porous metal-organicframework nanoscale carriers as a potential platform for drug delivery and imaging, Nat. Mater. 9 (2010) 172-178. doi:10.1038/nmat2608.

[12] A. Cabrera-Garcia, E. Checa-Chavarria, J. Pacheco-Torres, A. Bernabeu-Sanz, A. Vidal Moya, E. Rivero-Buceta, G. Sastre, E. Fernandez, P. Botella, Engineered contrast agents in a single structure for T1-T2 dual magnetic resonance imaging, Nanoscale. 10 (2018) 6349-6360. doi:10.1039/C7NR07948F.

[13] D. Wang, J. Zhou, R. Chen, R. Shi, G. Zhao, G. Xia, R. Li, Z. Liu, J. Tian, H. Wang, Z. Guo, H. Wang, Q. Chen, Controllable synthesis of dual-MOFs nanostructures for $\mathrm{pH}$-responsive artemisinin delivery, magnetic resonance and optical dual-model imaging-guided chemo/photothermal combinational cancer therapy, Biomaterials. 100 (2016) 27-40. doi:10.1016/j.biomaterials.2016.05.027.

[14] M. Lismont, L. Dreesen, S. Wuttke, Metal-organic framework nanoparticles in photodynamic therapy: current status and perspectives, Adv. Funct. Mater. 27 (2017) 1-16. doi:10.1002/adfm.201606314.

[15] W.H. Chen, X. Yu, W.C. Liao, Y.S. Sohn, A. Cecconello, A. Kozell, R. Nechushtai, I. Willner, ATP-responsive aptamer-based metal-organic framework nanoparticles (NMOFs) for the controlled release of loads and drugs, Adv. Funct. Mater. 27 (2017) 1-9. doi:10.1002/adfm.201702102. 
[16] W.H. Chen, W.C. Liao, Y.S. Sohn, M. Fadeev, A. Cecconello, R. Nechushtai, I. Willner, Stimuli-responsive nucleic acid-based polyacrylamide hydrogel-coated metal-organic framework nanoparticles for controlled drug release, Adv. Funct. Mater. 28 (2018) 1-9. doi:10.1002/adfm.201705137.

[17] W.H. Chen, X. Yu, A. Cecconello, Y.S. Sohn, R. Nechushtai, I. Willner, Stimuli-responsive nucleic acid-functionalized metal-organic framework nanoparticles using pH- and metal-ion-dependent DNAzymes as locks, Chem. Sci. 8 (2017) 5769-5780. doi:10.1039/c7sc01765k.

[18] C. Sun, C. Qin, X. Wang, Z. Su, Metal-organic frameworks as potential drug delivery systems, Expert Opin. Drug Deliv. 10 (2013) 89-101. doi: $10.1517 / 17425247.2013 .741583$.

[19] P. Horcajada, R. Gref, T. Baati, P.K. Allan, G. Maurin, P. Couvreur, Metalorganic frameworks in biomedicine, Chem. Rev. 112 (2012) 1232-1268. doi:dx.doi.org/10.1021/cr200256v.

[20] M. Giménez-Marqués, T. Hidalgo, C. Serre, P. Horcajada, Nanostructured metal-organic frameworks and their bio-related applications, Coord. Chem. Rev. 307 (2015) 342-360. doi:10.1016/j.ccr.2015.08.008.

[21] H. Bin Zhou, G.S. Liu, Z.J. Yao, Highly efficient and mild cascade reactions triggered by bis(triphenyl)oxodiphosphonium trifluoromethanesulfonate and a concise total synthesis of camptothecin, Org. Lett. 9 (2007) 2003-2005. doi:10.1021/ol0706307.

[22] L.L. Ezell, Edward L.; Smith, 1H- and 13C-NMR spectra of camptothecin and derivatives, J. Nat. Prod. 54 (1991) 1645-1650.

[23] V.J. Venditto, F.C. Szoka, Cancer nanomedicines: So many papers and so few 
drugs!, Adv. Drug Deliv. Rev. 65 (2013) 80-88.

doi:10.1016/j.addr.2012.09.038.

[24] A. Martinez, V. Palomo, D.I. Perez, C. Gil, Drugs in clinical development for the treatment of amyotrophic lateral sclerosis, Expert Opin. Investig. Drugs. 3784 (2017) 403-414. doi:10.1080/13543784.2017.1302426.

[25] M.S. S. Basili, Novel camptothecin derivatives as topoisomerase I inhibitors, Expert Opin. Ther. Pat. 19 (2009) 555-574. doi:10.1517/13543770902773437.

[26] J. Liu, L. Zhang, J. Lei, H. Shen, H. Ju, Multifunctional metal-organic framework nanoprobe for cathepsin B-activated cancer cell imaging and chemophotodynamic therapy, ACS Appl. Mater. Interfaces. 9 (2017) 2150-2158. doi:10.1021/acsami.6b14446.

[27] J. Zhuang, C.H. Kuo, L.Y. Chou, D.Y. Liu, E. Weerapana, C.K. Tsung, Optimized metal-organic-framework nanospheres for drug delivery: Evaluation of small-molecule encapsulation, ACS Nano. 8 (2014) 2812-2819. doi:10.1021/nn406590q.

[28] P. Botella, E. Rivero-Buceta, Safe approaches for camptothecin delivery: Structural analogues and nanomedicines, J. Control. Release. 247 (2017) 28-54. doi:10.1016/j.jconrel.2016.12.023.

[29] T. Čendak, E. Žunkovič, T.U. Godec, M. Mazaj, N.Z. Logar, G. Mali, Indomethacin embedded into MIL-101 frameworks: a solid-state NMR study, J. Phys. Chem. C. 118 (2014) 6140-6150. doi:10.1021/jp412566p.

[30] Y.B. Zhang, H. Furukawa, N. Ko, W. Nie, H.J. Park, S. Okajima, K.E. Cordova, H. Deng, J. Kim, O.M. Yaghi, Introduction of functionality, selection of topology, and enhancement of gas adsorption in multivariate metal-organic 
framework-177, J. Am. Chem. Soc. 137 (2015) 2641-2650.

doi:10.1021/ja512311a.

[31] P. Horcajada, H. Chevreau, D. Heurtaux, F. Benyettou, F. Salles, T. Devic, A. Garcia-Marquez, C. Yu, H. Lavrard, C.L. Dutson, E. Magnier, G. Maurin, E. Elkaïm, C. Serre, Extended and functionalized porous iron(III) tri- or dicarboxylates with MIL-100/101 topologies., Chem. Commun. 50 (2014) 6872-4. doi:10.1039/c4cc02175d.

[32] M. Taddei, K.C. Dümbgen, J.A. van Bokhoven, M. Ranocchiari, Aging of the reaction mixture as a tool to modulate the crystallite size of UiO-66 into the low nanometer range, Chem. Commun. 52 (2016) 6411-6414. doi:10.1039/C6CC02517J.

[33] S. Norbedo, F. Dinon, M. Bergamin, S. Bosi, V. Aroulmoji, R. Khan, E. Murano, Synthesis of 6-amino-6-deoxyhyaluronan as an intermediate for conjugation with carboxylate-containing compounds: application to hyaluronancamptothecin conjugates, Carbohydr. Res. 344 (2009) 98-104. doi:10.1016/j.carres.2008.09.027.

[34] X. Feng, J. Pinaud, E.L. Chaikof, D. Taton, Y. Gnanou, Sequential functionalization of janus-type dendrimer-like poly(ethylene oxide)s with camptothecin and folic acid, J. Polym. Sci. Part A Polym. Chem. 49 (2011) 2839-2849. doi:10.1002/pola.24718.

[35] M. Savonnet, D. Bazer-bachi, N. Bats, E. Jeanneau, V. Lecocq, C. Pinel, D. Farrusseng, Generic post-functionalization route from amino-derived metalorganic frameworks, J. Am. Chem. Soc. 68 (2010) 4518-4519. doi:10.1021/ja909613e.

[36] G. Tuci, A. Rossin, X. Xu, M. Ranocchiari, J.A. van Bokhoven, L. Luconi, I. 
Manet, M. Melucci, G. Giambastiani, "Click” on MOFs: a versatile tool for the multimodal derivatization of N3-decorated metal organic frameworks, Chem. Mater. 25 (2013) 2297-2308. doi:10.1021/cm400899a.

[37] Z. Wang, K.K. Tanabe, S.M. Cohen, Accessing postsynthetic modification in a series of metal-organic frameworks and the influence of framework topology on reactivity, Inorg. Chem. 48 (2009) 296-306. doi:10.1021/ic801837t.

[38] Z. Wang, S.M. Cohen, Postsynthetic modification of metal - organic frameworks, Chem. Soc. Rev. 38 (2009) 1315-1329. doi:10.1039/b802258p.

[39] S.M. Cohen, Postsynthetic methods for the functionalization of metal-organic frameworks, Chem. Rev. (2012) 970-1000. doi:10.1021/cr200179u.

[40] X. Li, A.K. Tjiptoputro, J. Ding, J.M. Xue, Y. Zhu, Pd-Ce nanoparticles supported on functional Fe-MIL-101-NH2: an efficient catalyst for selective glycerol oxidation, Catal. Today. 279 (2017) 77-83. doi:10.1016/j.cattod.2016.03.044.

[41] N. Subramanian, N. Sundaraganesan, S. Sudha, V. Aroulmoji, G.D. Sockalingam, M. Bergamin, Experimental and theoretical investigation of the molecular and electronic structure of anticancer drug camptothecin, Spectrochim. Acta - Part A Mol. Biomol. Spectrosc. 78 (2011) 1058-1067. doi:10.1016/j.saa.2010.12.049.

[42] C.D. Hein, X. Liu, D. Wang, Click chemistry, a powerful tool for pharmaceutical sciences, Pharm. Res. 25 (2008) 2216-2230. doi:10.1007/s11095-008-9616-1.

[43] M. Savonnet, E. Kockrick, A. Camarata, D. Bazer-Bachi, N. Bats, V. Lecocq, C. Pinel, D. Farrusseng, Combinatorial synthesis of metal-organic frameworks 
libraries by click-chemistry, New J. Chem. 35 (2011) 1892.

doi:10.1039/c1nj20350a.

[44] E. Bellido, M. Guillevic, T. Hidalgo, M.J. Santander-Ortega, C. Serre, P. Horcajada, Understanding the colloidal stability of the mesoporous MIL100(Fe) nanoparticles in physiological media, Langmuir. 30 (2014) 5911-5920. doi:10.1021/la5012555.

[45] P. Botella, I. Abasolo, Y. Fernández, C. Muniesa, S. Miranda, M. Quesada, J. Ruiz, S. Schwartz, A. Corma, Surface-modified silica nanoparticles for tumortargeted delivery of camptothecin and its biological evaluation, J. Control. Release. 156 (2011) 246-257. doi:10.1016/j.jconrel.2011.06.039.

[46] T.L. Riss, R.A. Moravec, A.L. Niles, S. Duellman, H.A. Benink, T.J. Worzella, L. Minor, Cell Viability Assays, in: Assay Guid. Man., Eli Lilly \& Company and the National Center for Advancing Translational Sciences, Bethesda, MD, 2012.

[47] I. Mellman, Y. Yarden, Endocytosis and Cancer, Cold Spring Harb Perspect Biol. 5 (2013) a016949. doi:10.1101/cshperspect.a016949.

[48] J. Cheng, K.T. Khin, G.S. Jensen, A. Liu, M.E. Davis, Synthesis of linear, Bcyclodextrin-based polymers and their camptothecin conjugates, Bioconjug. Chem. 14 (2003) 1007-1017. doi:10.1021/bc0340924.

[49] J.E. Diciccio, B.E. Steinberg, Lysosomal $\mathrm{pH}$ and analysis of the counter ion pathways that support acidification, J. Gen. Physiol. (2011) 385-390. doi:10.1085/jgp.201110596.

[50] L. Yan, X. Chen, Z. Wang, X. Zhang, X. Zhu, M. Zhou, W. Chen, L. Huang, V.A.L. Roy, P.K.N. Yu, G. Zhu, W. Zhang, Size controllable and surface 
tunable zeolitic imidazolate framework- 8 - poly ( acrylic acid sodium salt ) nanocomposites for $\mathrm{pH}$ responsive drug release and enhanced in vivo cancer treatment, ACS Appl. Mater. Interfaces. 9 (2017) 32990-33000.

doi:10.1021/acsami.7b10064.

[51] Q. Wu, M. Niu, X. Chen, L. Tan, C. Fu, X. Ren, J. Ren, L. Li, K. Xu, H. Zhong, X. Meng, Biocompatible and biodegradable zeolitic imidazolate framework / polydopamine nanocarriers for dual stimulus triggered tumor, Biomaterials. 162 (2018) 132-143. doi:10.1016/j.biomaterials.2018.02.022.

[52] S. Liu, Y. Ma, L. Gao, J. Pan, pH-responsive magnetic metal-organic framework nanocomposite: a smart porous adsorbent for highly specific enrichment of cis-diol containing luteolin, Chem. Eng. J. 341 (2018) 198-207. doi:10.1016/j.cej.2018.02.001.

[53] F. Duan, X. Feng, X. Yang, W. Sun, Y. Jin, H. Liu, K. Ge, Z. Li, J. Zhang, A simple and powerful co-delivery system based on $\mathrm{pH}$-responsive metal-organic frameworks for enhanced cancer immunotherapy, Biomaterials. 122 (2017) 2333. doi:10.1016/j.biomaterials.2017.01.017.

[54] W. Lin, Q. Hu, K. Jiang, Y. Cui, Y. Yang, G. Qian, A porous Zn-based metalorganic framework for $\mathrm{pH}$ and temperature dual-responsive controlled drug release, Microporous Mesoporous Mater. 249 (2017) 55-60. doi:10.1016/j.micromeso.2017.04.042.

[55] Y. Zhu, S. Chen, H. Zhao, Y. Yang, X. Chen, J. Sun, H. Fan, X. Zhang, PPy @ MIL-100 nanoparticles as a pH- and near-IR-irradiation-responsive drug carrier for simultaneous photothermal therapy and chemotherapy of cancer cells, ACS Appl. Mater. Interfaces. 8 (2016) 34209-34217. doi:10.1021/acsami.6b11378.

[56] A.M. Clemments, C. Muniesa, C.C. Landry, P. Botella, Effect of surface 
properties in protein corona development on mesoporous silica nanoparticles, RSC Adv. 4 (2014) 29134-29138. doi:10.1039/c4ra03277b.

[57] T. Simon-Yarza, M. Giménez-Marqués, R. Mrimi, A. Mielcarek, R. Gref, P. Horcajada, C. Serre, P. Couvreur, A smart metal - organic framework nanomaterial for lung targeting, Angew Chem Int Ed. 56 (2017) 15565-15569. doi:10.1002/anie.201707346.

[58] R. Ferrari, M. Lupi, C. Colombo, M. Morbidelli, M.D. Incalci, D. Moscatelli, Investigation of size, surface charge, PEGylation degree and concentration on the cellular uptake of polymer nanoparticles, Colloids Surf. B. 123 (2014) 639647.

[59] K.H. Min, K. Park, Y.S. Kim, S.M. Bae, S. Lee, H.G. Jo, R.W. Park, I.S. Kim, S.Y. Jeong, K. Kim, I.C. Kwon, Hydrophobically modified glycol chitosan nanoparticles-encapsulated camptothecin enhance the drug stability and tumor targeting in cancer therapy, J. Control. Release. 127 (2008) 208-218. doi:10.1016/j.jconrel.2008.01.013. 